\title{
An assessment of inversion methods for AEM data applied to environmental studies
}

David Beamish

Beamish, D., 2002.

An assessment of inversion methods for AEM data applied to environmental studies.

Journal of Applied Geophysics, 51, 75-96.

Key Words:

Airborne geophysics, electromagnetic methods, inversion, assessment of environmental influences

Corresponding author:

David Beamish

British Geological Survey, Keyworth, Nottingham, NG12 5GG, U.K.

Email: D.Beamish@bgs.ac.uk.

Tel: +44(0)1159363432

Fax: $+44(0) 1159363261$ 


\begin{abstract}
Airborne electromagnetic surveys are currently being flown over populated areas and applied to detailed problems using high flight line densities. Interpretation information is supplied through a model of the subsurface resistivity distribution. Theoretical and survey data are used here to study the character and reliability of such models. Although the survey data were obtained using a fixed-wing system, the corresponding associations with helicopter, towed-bird systems are discussed. Both Fraser half-space and 1D inversion techniques are considered in relation to their ability to distinguish geological, cultural and environmental influences on the survey data. Fraser half-space modelling provides the dual interpretation parameters of apparent resistivity and apparent depth at each operational frequency. The apparent resistivity was found to be a remarkably stable parameter and appears robust to the presence of a variety of at-surface cultural features. Such features provide both incorrect altitude data and multidimensional influences. Their influences are observed most strongly in the joint estimate of apparent depth and this accounts for the stability of the apparent resistivity. Positive apparent depths, in the example data, result from underestimated altitude measurements. It is demonstrated that increasingly negative apparent depths are associated with increasing misfits between a 1D model and the data. Centroid depth calculations, which are a transform of the Fraser half-space parameters, provide an example of the detection of non-1D influences on data obtained above a populated area. 1D inversion of both theoretical and survey data is examined. The simplest use of the 1D inversion method is in providing an estimate of a half-space resistivity. This can be undertaken prior to multi-layer inversion as an initial assessment. Underestimated altitude measurements also enter the problem and, in keeping with the Fraser pseudo-layer concept, an at-surface highly resistive layer of variable thickness, can be usefully introduced as a constrained parameter. It is clearly difficult to ascribe levels of significance to a 'measure' of misfit contained in a negative apparent depth with the dimensions of metres. The reliability of 1D models is better assessed using a formal misfit parameter. With the misfit parameter in place, the example data suggest that the 1D inversion methods provide reliable apparent resistivity values with a higher resolution than the equivalent information from the Fraser half-space estimates.
\end{abstract}




\section{Introduction}

Increasing use is being made of airborne electromagnetic (AEM) surveying for assessing infrastructure (Hodges, 1999; Beard and Lutro, 2000), groundwater (Fitterman and Deszcz-Pan, 1998; Sengpiel and Siemon, 1998), land-use and environmental issues (Puranen et al., 1999; Beamish and Kurimo, 2000). In a number of these cases the resistivity information may be provided at a high lateral resolution scale and in the vicinity of populated areas. The information is provided through a model and it is the character and reliability of the model that is considered here using both theoretical and survey data.

AEM surveying can employ frequency-domain or time-domain techniques, both of which are similar to ground-based counterparts (Collett, 1986). The frequency-domain systems, discussed here, exist as towed-bird configurations (typically Helicopter HEM systems) and as fixed-wing (wing-tip sensor) configurations. The frequencies employed in the two embodiments are similar; the main difference lies in the transmitter-receiver coil separation. HEM bird lengths are typically $<7 \mathrm{~m}$ and fixed-wing systems necessarily exceed this by a factor of about 3. A further difference lies in operational height above ground. Typically HEM operates the towed sensor bird about $30 \mathrm{~m}$ above ground level while fixed wing systems (with larger dipole moments) may be flown much higher. Early HEM and fixed wing systems used one or two simultaneous operating frequencies and these have been extended both in number and bandwidth.

EM induction by elevated magnetic dipoles is governed both by the frequency/bandwidth and the geometrical attributes of the system. Transmitter-receiver coil combinations include coplanar, coaxial and vertical and horizontal dipole configurations. The underlying coil-coil orientation issue has been discussed by a number of authors (Sengpiel, 1983; Liu and Becker, 1990; Kovacs et al., 1995). The dual frequency fixed-wing system, discussed here, uses a pair of vertical coplanar coils. In contrast to horizontal coplanar systems, the vertical coplanar coils provide an asymmetrical and smaller footprint when operated at the same height and frequency (e.g. Kovacs et al., 1995).

The fixed-wing AEM system developed and operated by the Geological Survey of Finland system was used in a series of trials in the U.K. to acquire detailed data sets in addition to magnetic gradiometer and radiometric information. Four areas in the East Midlands were surveyed. Three areas were surveyed at low elevation $(40 \mathrm{~m})$ using $50 \mathrm{~m}$ spaced flight lines. Particular targets for the EM data included environmentally sensitive zones around conurbations.

It is worth noting that, according to Holladay and Lo (1997), the Geological Survey of Finland is the only known operator of a frequency-domain, fixed-wing system and, as such, the current state-of-the-art is confined to two frequencies. A fixed-wing system offers operational and cost effectiveness over HEM systems when the intended use is in relation to providing systematic (i.e. year-on-year) multi-parameter, regional mapping. Many recent discussions of airborne EM data have involved quite specific targets such as hazardous waste-sites (Doll et. al., 2000), there are only a few examples of AEM applied to general 'land-quality' issues of the type considered here. 
When AEM surveys are carried out routinely over populated areas a number of issues are raised. The influence of buildings, services and forest cover become important. Although the problem of buildings is sometimes mentioned there are no specific case examples in the literature. A practical example is provided here.

A data acquisition rate of $4 \mathrm{~Hz}$ results in an along line sampling of $<15 \mathrm{~m}$. When data are acquired using a $50 \mathrm{~m}$ flight line separation and a wing-span of $21 \mathrm{~m}$ the coverage becomes quasi-continuous (Beamish, 2002). With these parameters, information is afforded at the site investigation scale. When used in geological and/or mineral exploration using, say, $200 \mathrm{~m}$ flight line separations, there is scope for the rejection of 'problem' data. At the site investigation scale, all data points require interpretation and the issues of at-surface and near-surface features and multidimensional effects have to be addressed. Although the rejection of problem data is sometimes mentioned (Sengpiel and Siemon, 1998) there are no case examples in the literature. A practical example is provided here.

Fraser half-space and 1D inversion procedures are examined using one of the acquired data sets. The study considers data obtained across the $4 \times 1.5 \mathrm{~km}$ Langar area (Fig. 1). The area has a distinctive (and conductive) geological background superimposed on which are a number of anomalies. The area contains one closed and one active domestic landfill, both of which give rise to conductive features. The environmental assessment is challenging in that it involves the detection of conductive pore fluids in conductive ( 5 ohm.m) clay-rich host rocks.

The interpretation of AEM data proceeds using one dimensional (1D) resistivity models. This study first considers the Fraser half-space parameters typically used in the interpretation of AEM data sets. Common procedures largely developed and described by Fraser $(1978,1986)$ comprise the modelling of the observed coupling ratios by a halfspace algorithm. Coupling ratios are here defined as the secondary to primary field ratio multiplied by $10^{6}$ for both the in-phase and in-quadrature components. The algorithm provides dual interpretation parameters (apparent resistivity and apparent depth) at each frequency. The two parameters are usually assessed jointly. Apparent depth can be negative, zero or positive and Fraser (1978) indicates that a negative apparent depth implies the model is a thin conductor over a resistor. Fraser $(1978$, p. 155) also describes a negative apparent depth as being 'not meaningful physically' because the absolute value of the negative depth is not a measure of the thickness of the conductive upper layer. The parameter is rarely presented in the literature but is used in the calculation of a wide variety of 'centroid' depth estimates (Siemon, 2001).

The dual parameters obtained are routinely used in a variety of approximate depth transforms. These procedures attempt to provide an effective (centroid) depth (Sengpiel, 1988) that can be associated with the resistivity value at a particular frequency. The simplification of the dipole source term used in the estimation of the dual parameters and centroid depth requires a coil separation $(r)$ to height $(h)$ ratio of $r<0.3 h$. In theory, the same procedures cannot be applied to our fixed-wing data collected at an elevation of $40 \mathrm{~m}$ yielding $\mathrm{r} / \mathrm{h}=0.53$. A study of the behaviour of the centroid calculation reveals the degree to which the existing procedures can be used directly or, where necessary, a correction applied. Fraser half-space parameters and centroid depths are presented in 
detail to examine their ability to differentiate geological, cultural (individual buildings and villages) and environmental (landfill) components.

Discrimination of invalid (e.g. non 1D) data adds to the reliability of an interpretation. 1D inversion of AEM data is becoming more widespread (Paterson and Redford, 1986; Sengpiel and Siemon, 1998) and the misfit parameter is useful with regard to model validity. Theoretical examples of 1D inversion applied to a two-layer earth are presented. Fraser half-space and 1D inversion resistivity models are compared over a $1 \times 1 \mathrm{~km}$ area containing a cement works and an active landfill (Fig. 1). The apparent depth information provided by the Fraser half-space algorithm is also considered. It is demonstrated that negative apparent depths are associated with increased misfit levels obtained by the 1D inversion procedure.

\section{The AEM survey data}

The first high resolution airborne EM surveys to address specific environmental issues in the U.K. were carried out jointly by the British (BGS) and Finnish (GTK) Geological Surveys in 1999. The dual frequency, fixed wing EM system operated by GTK was used in a series of trials to acquire detailed EM data sets in addition to magnetic gradiometer and radiometric information. Only the EM data are discussed here. Four areas in the English East Midlands were surveyed. Targets for the surveys included colliery spoil tips and domestic and industrial landfills (both active and closed).

The GTK fixed wing airborne EM system used in the surveys is described in detail by Poikonen et al. (1998). Jokinen and Lanne (1996) describe environmental applications of the system in Finland. Use of the system in relation to the mapping of surficial deposits is described by Puranen et al. (1999). The coils are wing-tip mounted (separation of $21.4 \mathrm{~m}$ ) and are vertical coplanar. Coupling ratios at two frequencies (3.1 and $14.4 \mathrm{kHz}$ ) are recorded simultaneously at $4 \mathrm{~Hz}$. The $3.1 \mathrm{kHz}$ data is referred to here as low frequency (LF) and the $14.4 \mathrm{kHz}$ data is referred to as the high frequency (HF) data. Sampling along the flight direction is typically between 10 and $15 \mathrm{~m}$. Elevation information is provided by a radar altimeter. The calibration of the system is described by Poikonen et al. (1998).

The airborne data are being assessed for their potential relevance to a number of landuse issues including waste planning and pollution control. Some of these issues require quite detailed, local scale $(<1 \mathrm{~km})$ information. Trial data were collected at two altitudes (40 $\mathrm{m}$ and $90 \mathrm{~m}$, depending on the area) using $50 \mathrm{~m}$ spaced flight lines to assess the siteinvestigation scale levels of performance. When airborne data are acquired over populated areas, coupling from both at- and near-surface cultural artefacts (e.g. buildings, pipelines, power lines, etc) may occur. The survey data contain examples of the many influences (geological, cultural and environmental) that pose a challenge to valid data interpretation.

One of the four test areas (Langar, Fig. 1) is a $4 \times 1.5 \mathrm{~km}$ area that was flown at an elevation of $40 \mathrm{~m}$ using $50 \mathrm{~m} \mathrm{E-W}$ flight lines. The area was chosen for a study of Fraser half-space and 1D inversion methods since the cultural features are relatively sparse and can be clearly identified. There is also very little in the way of tree cover. Since the detail 
in the data is important, results along a single profile (Line 420, Fig. 1) are used to illustrate the results. The profile traverses three roads, a cement works and an active domestic landfill.

\section{Fraser half-space processing}

The most common interpretation parameters obtained from frequency domain airborne EM surveys are those developed and described by Fraser (1978). Beard (2000) provides a recent comparison of these techniques. The concepts developed relate to the apparent half-space resistivity $\left(\rho_{a}\right)$ that can be deduced from the in-phase $(P)$ and in-quadrature (Q) coupling ratios measured by airborne systems. One of the modelling concepts is referred to as the pseudolayer half-space resistivity. In this model, the sensor altitude above ground level (as measured by a laser or radar altimeter), that may be in error, is not used in the calculation. The parameters obtained by the pseudo-layer half-space model are shown in Fig. 2.

Using the measured in-phase and in-quadrature coupling ratios at a single frequency, a curve matching (nomogram) algorithm is used to obtain the apparent resistivity of a halfspace. The 'curve' is actually 2 points and the procedure is exemplified in Beard (2000, Fig. 1). As a second parameter, the algorithm also returns an estimate of apparent distance ( $D_{a}$ in Fig. 2 ) to the ground surface. Since sensor altitude $(h)$ is also measured an apparent depth $\left(d_{a}\right)$ may be determined as:

$$
d_{a}=D_{a}-h
$$

When $d_{a}=0\left(D_{a}=h\right)$, the model is 'ideal' in the sense that there are no apparent discrepancies between the uniform half-space model and the data. When $d_{a}>0$, it is possible to account for the difference in $D_{a}$ and $h$ either by the presence of a resistive atsurface layer or by an incorrect (low) altitude measurement of $h$ (caused by tree cover or buildings). When $d_{a}<0$, the parameter suggests that the half-space is overlain by a more conductive, thin layer. The resistivity or thickness of the layer is not resolved. A negative value of $d_{a}$ can also result from a magnetic subsurface feature (Beard and Nyquist, 1998). Poor levelling of the data may also result in negative value of $d_{a}$. The survey data considered here come from relatively short flight lines and levelling accuracy is judged adequate.

The method provides dual interpretation parameters $\left(\rho_{a}, d_{a}\right)$ at each operating frequency. The stated advantage of the Fraser pseudo-layer half-space method is that the $\rho_{a}$ determinations are not influenced by errors in the altitude. The dual set of parameters $\rho_{a}(f), d_{a}(f)$ constitute the Fraser half-space interpretation parameters obtained from an airborne survey. The procedure and the parameters obtained appear very stable and this was probably an important consideration in previous decades when sensors and instrumentation were cruder. The procedure delivers a dual parameter set at every point sampled and no misfit (between model response and the two data points) is obtained. 
This is in contrast to the more common numerical 1D inversion schemes in which the misfit parameter is an important element in data and model interpretation.

Only a few papers dealing with the interpretation of acquired dual parameter data sets have appeared in the literature. One paper, which discusses both theoretical and observational aspects of the behaviour of apparent depth, is presented by Sengpiel (1983). The dual parameters are discussed in terms of both layered half-space models and in relation to conductors of finite extent (a thin conducting plate in a homogeneous halfspace). Negative apparent depths can occur in relation to both layered half-spaces and in relation to conductors of finite extent.

An example of the dual parameters obtained at two frequencies along the $3.5 \mathrm{~km}$ example profile (Line 420, Fig. 1) is shown in Fig. 3. Flight (sensor) altitude is also shown since this has a bearing on the interpretation. Fig. 3(a) shows the apparent resistivity values (logarithmic scale) with 2 roads, the cement works and the waste disposal site (see Fig. 1) indicated. The half-space resistivity estimates across the profile are relatively smooth functions. The background trends from about $30 \mathrm{ohm} . \mathrm{m}$ in the west to several ohm.m in the east can be associated with 3 geological units that traverse the area with a NE-SW trend. Along Line 420 the units comprise the Mercia Mudstone Group (472 to $472.7 \mathrm{~km}$ ), the Lower Lias Limestone ( 472.7 to $473.7 \mathrm{~km}$ ) and then a Lower Lias clay series (Fig. 1). The three units provide resistivities of about 25, 10 and 5 ohm.m respectively and the results therefore offer a degree of geological discrimination. Trends in the apparent depth results (lower frame) are less obvious. The $14.4 \mathrm{kHz}$ data are largely small and positive across the entire profile but the $3.1 \mathrm{kHz}$ data show a distinct negative level in the west. The apparent depths are largely confined to the range -5 to $5 \mathrm{~m}$. High wavenumber correlations exist between the $3.1 \mathrm{kHz}$ and $14.4 \mathrm{kHz}$ apparent depth results. These are probably due to the limited accuracy in distance $\left(D_{a}\right)$ calculation used in the curvematching algorithm and the common use of the height information in the estimates of apparent depth at the two frequencies.

Superimposed on the background trends are perturbations that can be associated with man-made features. In the apparent resistivity data, movements to lower values are observed in relation to two roads $(R)$, the cement works $(C)$ and within the waste disposal site (W). Flight altitude variations (Fig. 3b) range from 30 to $46 \mathrm{~m}$. Within the cement works zone (circled), three sharp movements to low values occur. These are identified as incorrect (in relation to ground height) low altitude values due to the presence of buildings. The apparent depth results (both frequencies) display an inverse correlation with the altitude movements and therefore, in this case, the apparent depth results may be used to identify the likely influence of buildings on the survey data. The responses due to two buildings within the cement works site are labelled as B1 and B2. In contrast to the behaviour of the apparent depth results, the apparent resistivity data remain smooth and stable since altitude information is not used in their determination.

\section{Approximate depth transforms}

In order to provide more useful depth information from multi-frequency survey data various approximate transforms have been suggested. The transforms all take as their 
starting point the dual parameters $\rho_{a}$ (a stable parameter) and $d_{a}$ (a parameter which may be difficult to interpret) at single frequencies as discussed above. Following the work of Mundry (1984), Sengpiel (1988) presented a centroid depth calculation that has proved very useful in the interpretation of survey data. The centroid depth calculation is a dipole field adaptation of similar concepts that were derived for low frequency plane-wave (magnetotelluric) investigations by Schmucker (1970) and Weidelt (1972).

The calculations are based on the complex transfer function C. For a half-space with resistivity $\rho$, the skin depth ( $p)$ in metres is given by:

$$
p=\left(\rho / \pi f \mu_{0}\right)^{1 / 2}
$$

Where $\mathrm{f}$ is frequency $(\mathrm{Hz})$ and $\mu_{0}=4 \pi 10^{-7} \mathrm{Vs} / \mathrm{Am}$. For our measuring frequencies the planewave skin depths are: $p(14.4 \mathrm{kHz})=4.19(\rho)^{1 / 2}$ and $p(3.1 \mathrm{kHz})=9.04(\rho)^{1 / 2}$. In the uniform field case the complex transfer function $\left(C_{o}\right)$ is:

$$
C_{o}=p / 2-i p / 2
$$

and has the dimensions of length. Following Weidelt (1972), the real part of the $C_{0}$ transfer function is equivalent to the depth $z_{0}$ of the centroid of the induced in-phase current system. The imaginary part of $C_{o}$ can be used to determine the apparent resistivity $\left(\rho_{0}\right)$ at the centroid depth $z_{0}$ :

$$
\rho_{o}=4 \mu_{0} \pi f(\operatorname{Im~C})^{2}
$$

with

$$
\mathrm{z}_{\mathrm{o}}=\operatorname{Re} \mathrm{C}_{\mathrm{o}}
$$

By joining $\rho_{0}, z_{0}$ paired values from a sequence of frequencies, an apparent resistivity depth profile (or sounding curve) is achieved.

If the source field can be characterised by a single wavenumber:

$$
\lambda=2 \pi L
$$

where $L$ is the wavelength of the source, the transfer function $C_{\lambda}$ for a half-space becomes:

$$
C_{\lambda}=\left[\lambda^{2}+([1+i] / p)^{2}\right]^{-1 / 2}
$$

If the primary field originates from an oscillating magnetic dipole, the resulting field components are represented by a continuous spectrum of wavelengths. Mundry (1984) used the integral for the normalised secondary magnetic field $(Z)$ for a magnetic dipole at a height $h$ above a homogeneous or layered half-space of Wait (1982):

$$
Z=r_{0}^{3} \int R_{0}(f, \lambda, \rho(z)) \lambda^{2} \exp (-2 \lambda h) J_{0}(\lambda r) d \lambda
$$


where $r$ is the separation between transmitter and receiver, $R_{\circ}$ is a reflection coefficient and $J_{0}$ is the Bessel function of order zero. The expression is valid for horizontal coplanar coils; in the case of vertical coplanar coils, the expression must be multiplied by 0.5 . The complex reflection factor is a function of the layered resistivity distribution $\rho(z)$ and the exponential function governs the propagation through air.

Mundry (1984) derived a simplified expression for $Z$ under the condition:

$$
h>3.3 r
$$

i.e. the sensor altitude exceeds the sensor separation by a factor greater than 3.3. Under this condition, the Bessel function $J_{0}$ may be replaced by unity and the parameter $r$ no longer appears under the integral. Condition (9) facilitates the determination of $\rho_{a}$ and $D_{a}$ (Mundry, 1984).

Sengpiel (1988) took the simplified Mundry integral and derived a relatively simple set of equations relating a complex transfer function $\mathrm{C}$ applicable to dipole induction and the inphase and in-quadrature components of the secondary field (Sengpiel, 1988; equations 22 and 23). The plane wave $\left(C_{0}\right)$ and dipolar (C) functions were compared with the remarkable result that the imaginary part of the transfer function for dipole induction was found to be virtually identical to that for induction by a plane wave source. The real part of the $C$ transfer function shows the strongest deviation from $C_{0}$ when the height $(h)$ is low in relation to the skin-depth and dipolar geometrical effects become significant.

Thus under the survey height condition (9), Sengpiel (1988) defined a centroid depth $\left(z^{*}\right)$ of the in-phase current system for dipole induction by analogy with Schmucker's $z_{0}$ for a uniform source field:

$$
\mathrm{z}^{*}=\mathrm{h} \operatorname{Re} \mathrm{C}
$$

The properties of the centroid depth have been investigated in a number of studies including 1D assessments (Sengpiel, 1988; Huang and Fraser, 1996) and in relation to multi-dimensional resistivity distributions (Sengpiel and Siemon, 1998; Sengpiel and Siemon, 2000).

The procedures involve taking the dual parameters $\rho_{a}, d_{a}$ and using $\rho_{a}$ as the resistivity estimate (i.e. $\rho^{*}=\rho_{\mathrm{a}}$ ) at a particular frequency. Replacing $\mathrm{h}$ in equation (10) by $D_{\mathrm{a}}$ leads to:

$$
\mathrm{z}_{\mathrm{s}}^{*}=\mathrm{D}_{\mathrm{a}} \operatorname{Re} \mathrm{C}
$$

where the centroid depth $z_{s}$ is measured from the surface of the equivalent half-space. Since we can assume that there are no currents flowing above the equivalent half-space, we can also measure the centroid depth from the true surface of the ground:

$$
z^{*}=d_{a}+D_{a} \operatorname{Re} C
$$


where $d_{a}$ is apparent depth. More recently Siemon (2001) found that by inserting $\rho=\rho_{a}$ into the skin-depth equation (2), the centroid depth can be simply calculated as:

$$
z_{p}{ }^{*}=d_{a}+p_{a} / 2
$$

where $p_{a}$ is the apparent skin-depth. A comparison of 1D theoretical sounding curves using $\rho_{a}\left(z^{*}\right)$ and $\rho_{a}\left(z_{p}{ }^{*}\right)$ is provided by Sengpiel and Siemon (2000).

\section{Data evaluation}

HEM systems typically operate with $r<7 m$ and use sensor (towed bird) elevations of greater than $21 \mathrm{~m}$ so that condition (9) is upheld. The fixed-wing survey data have a sensor separation of $21.34 \mathrm{~m}$ and the two main flight elevations were 40 and $90 \mathrm{~m}$. For the $90 \mathrm{~m}$ elevation data, condition (9) is satisfied, however, for the $40 \mathrm{~m}$ elevation data the condition is not met and dipolar geometrical effects may be significant.

The significance of the approximation on the centroid depth calculation was studied using equation (10) and the expressions given in Sengpiel (1988). Forward 1D numerical modelling was used to obtain estimates of $z^{*}$ for flight elevations in the range 20 to 120 $\mathrm{m}$ for a series of homogenous half-spaces. Fig. 4 shows the results obtained at high frequency (Fig. 4a) and at low frequency (Fig. 4b). The sensor separation ( $r$ ) used was $21.34 \mathrm{~m}$ and the vertical dashed lines indicate the altitude locations of $2 r$ and $3.3 r$ (condition (9)). At both frequencies, departures from the centroid values obtained at high elevation increase with increasing resistivity. At the high frequency there is very little change in the estimated value of the centroid depth values across the elevation range shown. At the low frequency the effect is more pronounced and in resistive environments, the centroid depth is likely to be underestimated when using low altitude survey data from fixed wing systems.

The results of Fig. 4 indicate that a centroid depth correction procedure can be applied, when necessary, to low altitude survey data. It is probably not worth attempting to obtain an already 'approximate' centroid depth to better than $1 \mathrm{~m}$. The centroid value differences for $40 \mathrm{~m}$ elevation at high frequencies when compared with values at $3.3 \mathrm{r}$ (Fig. 4) are all less than unity (for resistivities $<100$ ohm.m). At low frequencies the differences are $0.81 \mathrm{~m}$ (10 ohm.m), $1.5 \mathrm{~m}$ ( $50 \mathrm{ohm} . \mathrm{m})$ and $5.8 \mathrm{~m}$ (100 ohm.m).

The pseudo-layer half-space resistivities in the example data are all $<50$ ohm.m and, following the above discussion, no corrections to the centroid depth estimate given by (13) are required. The centroid depths along Line 420 are shown in Fig. 5. The influence of buildings (B1 and B2) is identified. Obviously, in this conductive environment, centroid depths are small being typically less than $15 \mathrm{~m}$ at both frequencies. Low frequency values increase in the west due to a geological transition to higher resistivity values. Elsewhere, the separation between the two sets of estimates is about $5 \mathrm{~m}$. In this conductive environment, the two frequencies are essentially sounding the same vertical profile and one would have to use a much wider frequency separation to detect any significant layering (if present). The centroid depths are a transform of information contained in the dual $\rho_{a}, d_{a}$ parameters; they inevitably reflect the geological and man-made features 
already discussed in relation to the dual parameters. The main utility of the centroid depth estimate is to provide an association between the $\rho_{a}$ estimates and depth below ground surface.

A further utility of the centroid depth lies in the discrimination of 'problem' or multidimensional data. As discussed by Schmucker (1987), for a 1D layered earth, Weidelt's second inequality (Weidelt, 1972; equation 2.31) ensures that $z^{*}$ increases monotonically with decreasing frequency. According to Sengpiel (1988) it is also valid for a dipole source if height remains constant. For data to be consistent with a 1D assumption, we have $z^{*}\left(f_{1}\right)<z^{*}\left(f_{2}\right)<z^{*}\left(f_{3}\right) \ldots$ etc where $f_{1}>f_{2}>f_{3} \ldots$ etc. In the example data of Fig. 5, the condition is satisfied even across the 'problem' area associated with the cement works. The utility of the centroid depth is better illustrated using the complete survey data for the area. Fig. 6(a) shows the survey flight lines across the area. Flight elevations were largely in the range from 30 to $50 \mathrm{~m}$ but the points with elevations $>50$ $\mathrm{m}$ have been identified with bold symbols. Three high-fly zones are identified as 1) the village of Barnstone in the north, 2) the village of Langar in the west (not overflown due to a local aerodrome) and 3) a zone of flight height adjustments in the east. In Fig. 6(b) the data points which represent $z^{*}(f=14.4 \mathrm{kHz})>z^{*}(f=3.1 \mathrm{kHz})$ and which are therefore inconsistent with a 1D assumption, have been identified by the bold symbols. In the north, there is an apparent association between the high-fly zone above the village of Barnstone and inconsistent data. It is important to realise, however, that the response data from the high-fly zones are adequate in terms of signal/noise (they would not normally be rejected on the basis of elevation). The centroid depth calculation allows a more rigorous identification of some, but not all, inconsistent data points. Such an identification allows the data to be rejected from the interpretation.

The approximate dipolar depth transforms can be further extended, again using an analogy with equivalent plane-wave magnetotelluric procedures, as discussed by Huang and Fraser (1996) and Sengpiel and Siemon (1998). The extended procedures are based on the Niblett-Bostick transform (Schmucker, 1987) and rely on the estimation of the gradient of the resistivity/frequency information (i.e. $d \rho_{a} / d f$ ) (Siemon, 2001). When the number of frequency estimates is greater than 2, a sounding curve is defined whose gradient may be estimated. When, as here, the number of frequencies is 2 , the curve is limited to a straight line. While such procedures may be applied in this case, the model is constrained to be a linear variation of resistivity with depth.

\section{1D inversion}

1D inversion procedures have been applied to both ground-based (meaning nonairborne)and airborne coil-coil systems. The weighted least-squares formalism is usually adopted and nonlinearity is addressed as part of the iterative procedure. One of the most common methods is the ridge-regression procedure (Inman, 1975) with stabilisation incorporated using a Marquardt (1970) approach. Paterson and Redford (1986) provide a description and examples of the problems associated with the 1D multilayer inversion of HEM data. One of the key points is that dual frequency airborne data provide an underdetermined case of model estimation i.e. the number of model parameters is greater than the number of observations. Ellis (1998) provides further insight into the 
inherent problem of non-uniqueness and incomplete bandwidth that typifies 1D inversion of airborne data. Sengpiel and Siemon $(1998,2000)$ discuss a Marquardt multilayer inversion applied to modern five frequencies HEM data.

The correct choice of the number of layers (that can be resolved by the data) is a difficult problem. The number of layers is an unknown for each multilayer inversion problem. The 'correct' choice is both site specific (it depends on the resistivity structure encountered) and system specific (it depends on the number of frequencies, their separation and their bandwidth). It is always possible to increase the number of layers beyond those 'present' and, typically, reduce the misfit. However the problems of parameter equivalence and resolution of the 'additional' layers are known and have been discussed widely (e.g. Ellis, 1998).

A theoretical example of the problem that arises in the case of the two frequency fixedwing system is now considered. Forward modelling of a two-layer case was used to obtain a series of theoretical data. The elevation adopted was $40 \mathrm{~m}$ and the coil spacing was $21.34 \mathrm{~m}$. The two layer model comprises a first layer with a resistivity of $40 \mathrm{ohm} . \mathrm{m}$ above a $10 \mathrm{ohm} . \mathrm{m}$ half-space. The interface depth was allowed to vary between 0 (i.e. a 10 ohm.m half space) and $80 \mathrm{~m}$ (effectively a $40 \mathrm{ohm} . \mathrm{m}$ half space). A Marquardt non-linear least-squares inversion algorithm, adapted for airborne EM, was applied to the theoretical data.

For the small numbers of observations used in the inversion (e.g. 2), an L1 norm (based on the sum of differences) rather than an L2 norm (based on the sum of squared differences) misfit parameter has proved useful. The issues involved are those of robust statistics (Hampel et al., 1986). Here the L1 norm percentage error is defined as:

$$
L 1(\%)=100.0 \quad \sum_{i=1}^{n}\left|O_{i}-C_{i}\right| / C_{i}
$$

where $O_{i}$ is the $i^{\prime}$ th observation (an in-phase or in-quadrature coupling ratio) and $C_{i}$ is the corresponding calculated value. L1 norms are typically greater than L2 norms (e.g. an rms misfit) by a factor of 10 . This definition of misfit is used throughout.

The results of constructing a half-space solution (1 layer) to each of the two frequency data sets by inverse modelling are shown in Fig. 7. The model half-space resistivities are shown in Fig. 7(a) and the percentage misfit between data and model is shown in Fig. 7(b).Apart from the first data point (an interface depth of zero indicates a half-space of 10 ohm.m) the initial set of half-space resistivities (interface depths from 1 to $20 \mathrm{~m}$ ) returned by the inversion are 'failed' attempts to provide a single half-space resistivity to the twolayer data. The model resistivities are, however, contained within the correct range from 10 to $40 \mathrm{ohm} . \mathrm{m}$. As the thickness of the first layer increases, the higher frequency data approach a correct layer value when the interface depth is $18 \mathrm{~m}$. The lower frequency results, with a larger electromagnetic scale length, continue to ' $\mathrm{mix}^{\prime}$ ' the two resistivities present until an interface depth of about $40 \mathrm{~m}$. The misfit values reflect the behaviour 
observed in the resistivity estimates. The misfit obtained for the higher frequency estimation peaks more rapidly, then decays more rapidly than that of the lower frequency inversion.

The above example relates to the pitfalls of applying an incorrect model within a fixed number of layers assumed in the inversion procedure. When the number of layers is appropriate, multilayer inversion schemes can provide extremely accurate results. A two layer inversion procedure applied to the joint two frequency theoretical data set provided the model results shown in Fig. 8. In this case the estimated model parameters are the resistivities of layer 1 (resistivity $40 \mathrm{ohm} . \mathrm{m}$ ) and layer 2 (resistivity $10 \mathrm{ohm} . \mathrm{m}$ ) together with their calculated interface depth. The misfits obtained in this case are all less than 0.001 .

\section{1D inversion: Application to survey data}

The number of degrees of freedom (input data) obtained with the fixed wing system is four ( 2 data points at 2 frequencies). In theory, the estimation of a 2-layer model would involve a slightly overdetermined inversion procedure since the number of model parameters in this case is 3 . In practice this is only correct when the altitude measurement is a reliable estimate of height above ground level. The radar altimeter used has a resolution of $0.1 \mathrm{~m}$ and an accuracy of $0.5 \mathrm{~m}$. The instrumental accuracy is not an issue. Barometric height, although recorded, was found to be unreliable. The real issue is that, when surveying in populated areas, the height above ground level is often incorrectly determined (biased to incorrect low values) due to a variety of elevated features. The most obvious features are well-defined forest and copse zones together with domestic, commercial and agricultural buildings.

In order to maintain detailed inversion model accuracy it has been necessary, in general, to introduce an initial very high resistivity first layer. This procedure is, in effect, a formalism in keeping with the pseudo-layer half space solution discussed previously. The first layer resistivity (e.g. $10^{6} \mathrm{ohm} . \mathrm{m}$ ) is a constrained parameter but its thickness is allowed to vary. The simplest inversion strategy is thus to provide a fixed layer above a half-space model for each of the recorded frequencies. The procedure is then equivalent to that of the pseudo-layer half space model (Fig. 2). The two parameters estimated are the thickness (of layer 1 ) and the underlying half-space resistivity.

The results obtained, along example Line 420, for the low frequency data are shown in Fig. 9. In this case, the baseline has been restricted to a $1 \mathrm{~km}$ profile length across the cement works and waste disposal site. The resistivity, shown as a solid line in Fig. 9(a), is compared with that obtained from the pseudo-layer algorithm (symbols). A strong overall level of correspondence between the two sets of estimates is observed. In detail, it is clear that the Fraser pseudo-layer estimates are spatially smooth while the 1D inversion estimates contain a number of higher wavenumber components. The thickness of the atsurface resistive layer is shown in Fig. 9(b). The influence of the buildings (B1 and B2) is again observed. The misfit error (Fig. 9c) displays no correlation with the thickness estimates. This suggests that the influence of the buildings is restricted to an incorrect elevation error rather than, say, their multi-dimensional effects. Towards the centre of 
the profile, the misfit estimates exceed $10 \%$, and display some correspondence with fluctuations in the resistivity estimates.

The observed (symbols) and two layer inversion modelled (line) data at both frequencies are compared in Fig. 10(a,b). These are the data from which the misfits are derived however the plots serve to demonstrate the detailed behaviour of the misfit in relation to the observations in both $\mathrm{P}$ and $\mathrm{Q}$ components. For those not familiar with the 'raw' coupling data from airborne systems, the overall level of coupling (e.g. 10000 ppm) is determined by the subsurface resistivity. The large scale movements are determined by variations in flight altitude (see Fig. 3). Any lateral changes in the resistivity structure may be detected at the tens of ppm level and would only be observed in Fig. 10 by slight changes in gradient. It is the high wavenumber fluctuations in misfit that are of interest. The apparent depth estimates, obtained from the pseudo-layer algorithm, are shown in Fig. 10(c). The building response features (B1, B2) are evident. The high wavenumber features in the data elsewhere, however, display a correspondence with fluctuations in the modelled response estimates that provide the largest misfits. It appears that, although the pseudo-layer algorithm provides no misfit values, some level of misfit information is contained within the estimates of apparent depth.

Misfit values obtained from 1D inversion procedures are of great utility in both the large scale and detailed interpretation of the applicability of a given model. Fig. 11(a) shows the low frequency misfit values over the whole survey area classified into two sets of symbols at the $10 \%$ error level. The data set shown has first been winnowed following application of Weidelt's second inequality applied to centroid depths (see Fig. 6). Points with a misfit $>10 \%$ account for $18 \%$ of the total. If the same level is applied to the high frequency data, less than $2 \%$ are included. The high frequency misfit values in Fig. 11(b) have therefore been classified at the $5 \%$ error level.

Apparent in the NW corner of the area is a continuous zone that displays higher levels of error at both frequencies. This is interpreted as an area in which a half-space solution is not completely appropriate. The behaviour implies that multilayer (possibly 2 layer) inversion of the joint two frequency data would be required to reduce the misfit. The zone, which has higher resistivities (see Fig. 3), correlates with the known geology and comprises an area of alluvial cover over Mercia Mudstone trending NE-SW. These are the only alluvial deposits within the survey area. Somewhat surprisingly, the linear road (or features associated with the road), most evident at low frequencies, provides a lower misfit than the surrounding area. Elsewhere, high error levels tend to occur as small clusters or individual data points.

The ability of the apparent resistivity data sets to discriminate features at the site investigation scale is now examined. The $1 \times 1 \mathrm{~km}$ area centred on the cement works and active waste disposal site, shown in Fig. 1, is considered using the low frequency data. As stated previously, the two survey frequencies provide nearly equivalent information in this conductive environment. The apparent resistivities obtained from the Fraser pseudolayer half-space method are shown in Fig. 12(a) with an overlay of an Ordnance Survey (1:25k) map. Two highly conductive zones, already observed along Line 420, are resolved. Line 420 is located along the Northing of $335 \mathrm{~km}$. The most conductive feature (about 1 ohm.m) is highly localised and is centred on the cement works. A more diffuse anomaly ( 2 
to 4 ohm.m) is centred on the landfill. Overall the apparent resistivity data appear smooth and stable.

The apparent resistivities obtained from the 1D inversion, including rejection of data points at the $10 \%$ error level, are shown in Fig. 12(b). The gridding (kriging) and contour levels selected are the same as in the previous case. The two resistivity maps show a broad level of agreement however the 1D inversion results display a set of higher wavenumber features that appear realistic when the data density is considered (see below). If we were to define a resistivity level of $<4$ ohm.m as anomalous and of interest in relation to enhanced concentrations of pore fluids then the two sets of results would provide different conclusions (in detail). The Fraser half-space data would indicate two highly compact zones centred on the works and landfill. The 1D inversion results would indicate the same source centres but with a more complex and extensive subsurface volumetric contribution. Without geochemical borehole sampling information the degree of appropriateness of each model cannot be assessed. At present the Fraser half-space results are treated as a correct but conservative model; the 1D inversion results are treated as a correct guide to ground-truth studies.

The apparent depth information provided by the Fraser pseudo-layer algorithm should also be considered in relation to the interpretation of the resistivity data. These data are shown in Fig. 13(a) in conjunction with the flight line data points sampled by the contoured information. Values in the range 0 to $2 \mathrm{~m}$ predominate and only negative values $(0$ to $-6 \mathrm{~m})$ are shown. Fig. 13(b) shows the misfit error level (no rejection) obtained from 1D inversion. Only misfit values of $>7 \%$ are contoured. Although the dynamic ranges of the two parameters are very different it is clear that there is a strong correspondence between increasingly negative apparent depth and increasing misfit. The results suggest that model fitting errors in the Fraser pseudo-layer algorithm are accounted for by the introduction of negative apparent depths. As has been demonstrated, positive apparent depths do indeed account for incorrect altitude estimates or may indicate at-surface resistive zones. The further observation that misfit is also contained in the parameter serves to explain the fact that the jointly estimated apparent resistivity is a stable and conservative first estimate of the resistivity distribution.

Finally, it is worth noting that the negative apparent depths in the example are small. Other data sets contain negative apparent depths that exceed the survey altitude. The units of negative apparent depth are metres and a level of significance has to be established if a rejection criterion is applied. The 1D inversion methods can provide misfit estimates that have well-established credentials for testing the significance of the modelled parameters.

\section{Conclusions}

The present study has considered the applicability of Fraser half-space and 1D inversion methods applied to high-resolution AEM data. It is recognised that a number of interpretation and modelling issues arise due to the imprecise measurement of sensor 
altitude with respect to ground level. These issues become acute when surveys are conducted in populated areas. Two possible improvements to aid modelling would be for the on-board avionics to record accurate (sub-metric) barometric height (e.g. Sengpiel and Siemon, 2000) in addition to radar height or to establish equivalent accuracies in the elevation information provided by differential global positioning systems already used for position information.

Modern fixed-wing AEM data can be obtained at high spatial resolution and used for assessments of environmental influences on the near-surface resistivity distribution. The ability of the data and processing methods to differentiate geological, cultural and environmental influences is then an important factor. The area chosen for the study contains examples of all three influences with the latter two occurring in relatively sparse and identifiable fashion.

Fraser half-space modelling provides the dual interpretation parameters of apparent resistivity and apparent depth at each operational frequency. The apparent resistivity is a remarkably stable parameter and appears robust to the presence of a variety of atsurface cultural features. Such features provide both incorrect altitude and multidimensional influences. Their influences are partly incorporated into the joint estimate of apparent depth and this accounts for the stability of the estimated apparent resistivity. Positive apparent depths, in the example data, can result from underestimated altitude measurements. Increasingly negative apparent depths are associated with increasing misfits between the 1D half-space model response and the observed data.

The estimate of apparent depth can be used, in conjunction with apparent skin-depth (incorporating apparent resistivity), as the basis for an approximate depth transform. This transform, a dipolar adaptation of plane wave techniques, provides a centroid depth under the condition that the sensor altitude exceeds the sensor separation by a factor $>$ 3.3. Since this condition is not satisfied by low altitude, fixed-wing survey data the theory of the centroid depth calculation was examined. The study reveals the degree to which the existing procedures can be used directly, or where necessary, a correction applied. Corrections become increasingly necessary at low frequencies and in resistive environments. The conditions under which existing depth transforms can be applied to fixed-wing surveys have not previously been described.

In a 1D environment centroid depths must increase with decreasing frequency. This condition can be used to flag or reject inappropriate data and models. In the featured example survey, a swathe of such inappropriate data are associated with measurements obtained above a village. In contrast, data obtained above isolated and individual buildings, although influenced, were still classified as appropriate using centroid depths.

1D least-squares inversion of both theoretical and survey data has been examined. The issue of depth resolution and number of layers used by $1 \mathrm{D}$ methods is always related to the number of available frequencies and their bandwidth. The simplest use of the 1D inversion methods is in providing an estimate of a half-space resistivity. This can be undertaken prior to multi-layer inversion as an initial assessment. Erroneous altitude measurements also enter the problem and, in keeping with the Fraser pseudo-layer concept, an at-surface highly resistive layer of variable thickness, can be usefully 
introduced as a constrained parameter. Multi-layer inversion of the dual frequency data has also been conducted. As has already been stated, in this conductive environment, the two frequencies are essentially sounding the same vertical profile and one would have to use a much wider frequency separation to detect any significant layering (if present).

A detailed comparison of Fraser half-space and equivalent 1D inversion model parameters has led to a better understanding of the Fraser half-space parameters, particularly that of apparent depth. It is clearly difficult to ascribe levels of significance to a 'measure' of misfit contained in a negative apparent depth with the dimensions of metres. The reliability of 1D models is better assessed using a formal misfit parameter. With the misfit parameter in place, the example data suggest that the 1D inversion methods provide reliable resistivity models with a higher resolution than the equivalent information from Fraser half-space estimates. At present the pseudo-layer results are treated as a simplified conservative model; the 1D inversion results are treated as a correct guide to ground-truth studies.

\section{Acknowledgements}

The survey data discussed here were obtained as a collaborative venture between the British and Finnish Geological Surveys (BGS and GTK). The BGS wishes to thank Maija Kurimo and the GTK team for their dedication and professionalism during the survey operations. We are grateful to the Department of the Environment, Transport and the Regions and the Environment Agency for their co-sponsorship of the acquisition of the survey data. This report is published with the permission of the Executive Director, British Geological Survey (NERC).

\section{References}

Beamish, D., Kurimo, M., 2000. Trial airborne EM surveys to assess minewater pollution in the UK. 62 ${ }^{\text {nd }}$ EAGE Conference and Technical Exhibition, Glasgow, UK. Expanded Abstracts, Vol. 1, D-22.

Beamish, D., 2002. Airborne EM footprints. Geophys. Prospect., submitted.

Beard, L.P., Nyquist, J.E., 1998. Simultaneous inversion of airborne electromagnetic data for resistivity and magnetic permeability. Geophysics. 63, 1556-1564.

Beard, L.P., Lutro, O., 2000. Airborne geophysics and infrastructure planning - a case study, J. Environ. Engin. Geophys. 5, 1-10.

Beard, L.P., 2000. Comparison of methods for estimating earth resistivity from airborne electromagnetic measurements. J. Appl. Geophys. 45, 239-259.

Collett, L.S., 1986. Development of the airborne electromagnetic technique. In: Palacky, G.J. (Ed.), Airborne Resistivity Mapping, Geological Survey of Canada, Paper 86-22, pp. 927. 
Doll, W.E., Nyquist, J.E., Beard, L.P., Gamey, T.J., 2000. Airborne geophysical surveying for hazardous waste site characterisation on the Oak Ridge Reservation, Tennessee. Geophysics 65, 1372-1387.

Ellis, R.G., 1998. Inversion of airborne electromagnetic data. Exploration Geophysics 29, 121-127.

Fitterman, D.V., Deszcz, M., 1998. Helicopter EM mapping of saltwater intrusion in Everglades National Park. Exploration Geophysics 29, 240-243.

Fraser, D.C., 1978. Resistivity mapping with an airborne multicoil electromagnetic system. Geophysics 43, 144-172.

Fraser, D.C., 1986. Dighem resistivity techniques in airborne electromagnetic mapping. In: Palacky, G.J. (Ed.), Airborne Resistivity Mapping, Geological Survey of Canada, Paper 8622, pp. 49-54.

Hampel, F.R., Ronchetti, E.M., Rousseeuw, P.J., Stahel, W.A., 1986. Robust Statistics. The approach based on influence functions. Wiley, New York.

Hodges, G., 1999. A world of applications for helicopter electromagnetics to environmental and engineering problems. SAGEEP Extended Abstracts, Oakland, California, pp 899-907.

Holladay, S., Lo, B., 1997, Airborne frequency-domain EM - Review and preview. In: Gubins, A.G. (Ed.), Proceedings of Exploration 97: Fourth International Conference on Mineral Exploration, pp. 505-514.

Huang, H., Fraser, D.C., 1996. The differential parameter method for multifrequency airborne resistivity mapping. Geophysics 55, 1327-1337.

Inman, J.R., 1975. Resistivity inversion with ridge regression. Geophysics, 40, 798-817.

Jokinen, T., Lanne, E., 1996. Airborne geophysics in mapping contaminant plumes from landfills. SAGEEP Extended Abstracts, Keystone, Colorado, pp. 981-995.

Kovacs, A., Holladay, J.S., Bergeron Jr., C.J., 1995. The footprint/altitude ratio for helicopter electromagnetic sounding of sea-ice thickness: Comparison of theoretical and field estimates. Geophysics 60, 374-380.

Liu, G., Becker, A., 1990. Two-dimensional mapping of sea-ice keels with airborne electromagnetics. Geophysics, 55, 239-248.

Marquardt, D.W., 1970. Generalized inverses, ridge regression, biased linear estimation and nonlinear estimation. Technometrics 12, 591-612. 
Mundry, E., 1984. On the interpretation of airborne electromagnetic data for the twolayer case. Geophys. Prospect. 32, 336-346.

Paterson, N.R., Redford, S.W., 1986. Inversion of airborne electromagnetic data for overburden mapping and groundwater exploration. In: Palacky, G.J. (Ed.), Airborne Resistivity Mapping, Geological Survey of Canada, Paper 86-22, pp. 39-48.

Poikonen, A., Sulkanen, K, Oksama, M., Suppala, I., 1998. Novel dual frequency fixed wing airborne EM system of Geological Survey of Finland (GTK). Exploration Geophysics 29, 4651.

Puranen, R., Säävuori, H., Sahala, L., Suppala, I., Mäkilä, M., Lerssi, J., 1999. Airborne electromagnetic mapping of surficial deposits in Finland. First Break, May 1999, 145-154.

Schmucker, U., 1970. Anomalies of Geomagnetic Variations in the Southwestern United States. Bull. Scripps Inst. Oceanogr. 13, 1-165, La Jolla, CA.

Schmucker, U., 1987. Substitute conductors for electromagnetic response estimates. PAGEOPH 125, 341-367.

Sengpiel, K.-P., 1983. Resistivity/depth mapping with airborne electromagnetic survey data. Geophysics 48, 181-196.

Sengpiel, K.-P., 1988. Approximate inversion of airborne EM data from a multi-layered ground. Geophys. Prospect. 36, 446-459.

Sengpiel, K.-P., Siemon, B., 1998. Examples of 1-D inversion of multifrequency HEM data from 3-D resistivity distribution. Exploration Geophysics 29, 133-141.

Sengpiel, K.-P., Siemon, B., 2000. Advanced inversion methods for airborne electromagnetic exploration. Geophysics 65, 1983-1992.

Siemon, B., 2001. Improved and new resistivity-depth profiles for helicopter electromagnetic data. J. Appl. Geophys. 46, 65-76.

Wait, J.R., 1982. Geo-Electromagnetism. Academic Press, New York.

Weidelt, P., 1972. The inverse problem of geomagnetic induction. Z. Geophys. 38, 257289. 


\section{Figure Captions}

Figure 1. Location map of the Langar example survey area. Cross symbol denotes the position of the closed landfill; the open circle indicates the central position of the active landfill. Flight line 420 is indicated (along Northing $335 \mathrm{~km}$ ). Central $1 \times 1 \mathrm{~km}$ square is centred on a cement works (labelled Works) and the active landfill. The heavy dash lines indicate 3 main geological units, from NW to SE they comprise the Mercia Mudstone Group, a Lower Lias Limestone and a further clay rich member of the Lower Lias. The base map is reproduced from the OS map by British Geological Survey with the permission of Ordnance Survey on behalf of The Controller of Her Majesty's Stationery Office, (C) Crown copyright. All rights reserved.

Figure 2. Illustration of parameter relationships involved in the pseudo-layer half-space calculation. The sensor separation is $r$. The on-board altimeter provides a correct elevation of $h$ or underestimated $h *$ when elevated features are encountered. Apparent distance (to half-space) is $D_{a}$ and formulae give the apparent depth $\left(d_{a}\right)$ below ground surface.

Figure 3. Fraser pseudo-layer half-space parameters along E-W flight line 420. (a) apparent resistivities at $3.1 \mathrm{kHz}$ (LF) and $14.4 \mathrm{kHz}$ (HF). Positions of two roads (R), the cement works (C) and the waste disposal site (W) are indicated. (b) Apparent depth at 3.1 $\mathrm{kHz}(\mathrm{LF})$ and $14.4 \mathrm{kHz}(\mathrm{HF})$, together with flight altitude (ALT, right axis). Circle denotes perturbations caused by buildings (B1 and B2) in the cement works area.

Figure 4. Centroid depths calculated for 3 half-space resistivities and for elevations in the range 20 to $120 \mathrm{~m}$ using a sensor separation (r) of $21.34 \mathrm{~m}$. (a) $14.4 \mathrm{kHz}$ (HF). (b) $3.1 \mathrm{kHz}$ (LF).

Figure 5. Centroid depths along E-W flight line 420 at $3.1 \mathrm{kHz}$ (LF) and $14.4 \mathrm{kHz}$ (HF). The influence of buildings B1 and B2 is indicated.

Figure 6. Results shown as classified symbol values along flight lines for the Langar survey area. (a) Elevation, values from 26 to $50 \mathrm{~m}$ shown as light symbols, values $>50 \mathrm{~m}$ shown as bold circles. The two ellipses denote the villages of Barnstone (B) and Langar (L). (b) Bold symbols denote points where the centroid depth $z^{*}(14.4 \mathrm{kHz})>z^{*}(3.1 \mathrm{kHz})$.

Figure 7. 1D inversion results for theoretical data from a 2-layer case with a 40 ohm.m cover above a $10 \mathrm{ohm} . \mathrm{m}$ halfspace, with interface depths ranging from 0 (a $10 \mathrm{ohm} . \mathrm{m}$ halfspace) to $80 \mathrm{~m}$. The inversion attempts to fit a half-space model for each of the two frequencies ( $L F=3.1 \mathrm{kHz}, \mathrm{HF}=14.4 \mathrm{kHz}$ ). (a) apparent resistivities (ohm.m). (b) misfit (\%) calculated according to equation (14).

Figure 8. 1D inversion results for theoretical data from a 2-layer case with a 40 ohm.m cover above a $10 \mathrm{ohm} . \mathrm{m}$ halfspace, with interface depths ranging from 0 (a $10 \mathrm{ohm} . \mathrm{m}$ halfspace) to $80 \mathrm{~m}$. The inversion attempts to fit a 2-layer model using both frequencies. 
(a) resistivity of Layer 1 (ohm.m). (b) resistivity of Layer 2 (ohm.m). (c) depth of interface (m).

Figure 9. Half-space model results obtained along the central $1 \mathrm{~km}$ profile of E-W flight line 420. (a) LF (3.1 kHz) apparent resistivity. Fraser pseudo-layer half-space (symbols), 1D inversion (line). (b) Thickness of resistive at-surface layer (1D inversion), with influence of buildings (B1, B2) noted. (c) Misfit (\%) calculated according to equation (14).

Figure 10. Half-space model results obtained along the central $1 \mathrm{~km}$ profile of E-W flight line 420. (a) Comparison of LF (3.1 kHz) coupling ratios, observed (symbol) and modelled (line), in-phase (P) and in-quadrature (Q) components. (b) Comparison of HF (14.4 kHz) coupling ratios, observed (symbol) and modelled (line), in-phase (P) and in-quadrature (Q) components. (c) LF and HF apparent depth estimates obtained from Fraser pseudo-layer half-space algorithm, with influence of buildings (B1, B2) noted.

Figure 11. 1D inversion misfits shown as classified symbol values along flight lines for the Langar survey area. Data have been pre-processed according to Weidelt's inequality condition applied to centroid depth. (a) LF ( $3.1 \mathrm{kHz}$ ) misfit, values from 0 to $10 \%$ shown as light symbols, values $>10 \%$ shown as bold circles. (b) $\mathrm{HF}(14.4 \mathrm{kHz})$ misfit, values from 0 to $5 \%$ shown as light symbols, values $>5 \%$ shown as bold circles.

Figure 12. Comparison of (a) Fraser half-space and (b) 1D inversion, LF (3.1 kHz) half-space resistivity results across the central $1 \times 1 \mathrm{~km}$ area containing cement works and land-fill. The base map is reproduced from the OS map by British Geological Survey with the permission of Ordnance Survey on behalf of The Controller of Her Majesty's Stationery Office, (c) Crown copyright. All rights reserved.

Figure 13. Comparison of (a) negative apparent depth and (b) 1D inversion misfit for LF $(3.1 \mathrm{kHz})$ half-space results across the central $1 \times 1 \mathrm{~km}$ area containing cement works and land-fill. (a) Only negative apparent depths $(0$ to $-6 \mathrm{~m})$ are contoured. (b) Only misfits > $7 \%$ are contoured. Background shows data sampling density of E-W flight lines. 


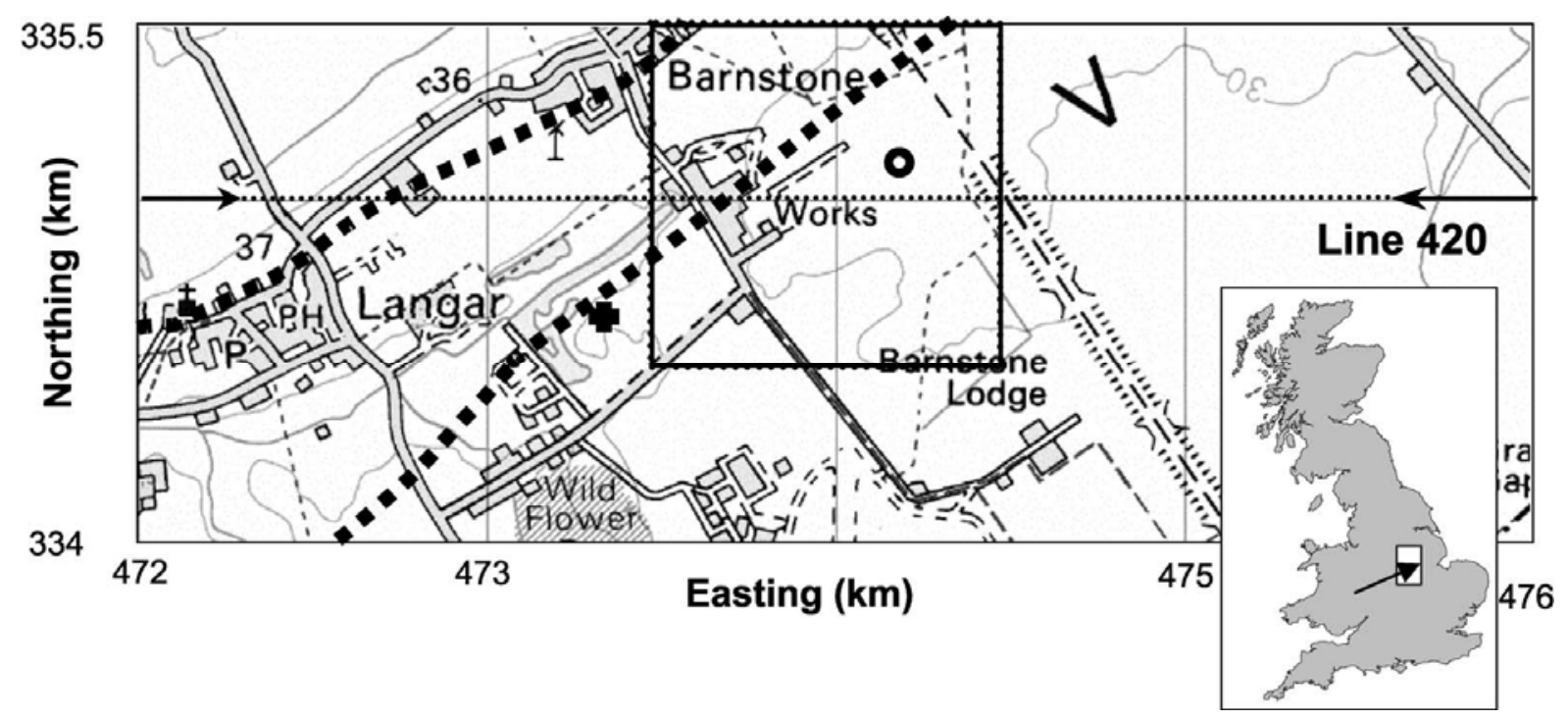

Figure 1. Location map of the Langar example survey area. Cross symbol denotes the position of the closed landfill; the open circle indicates the central position of the active landfill. Flight line 420 is indicated (along Northing $335 \mathrm{~km}$ ). Central $1 \times 1 \mathrm{~km}$ square is centred on a cement works (labelled Works) and the active landfill. The heavy dash lines indicate 3 main geological units, from NW to SE they comprise the Mercia Mudstone Group, a Lower Lias Limestone and a further clay rich member of the Lower Lias. The base map is reproduced from the OS map by British Geological Survey with the permission of Ordnance Survey on behalf of The Controller of Her Majesty's Stationery Office, (C) Crown copyright. All rights reserved. 
Tx coil pair $\quad$ Rx coil pair

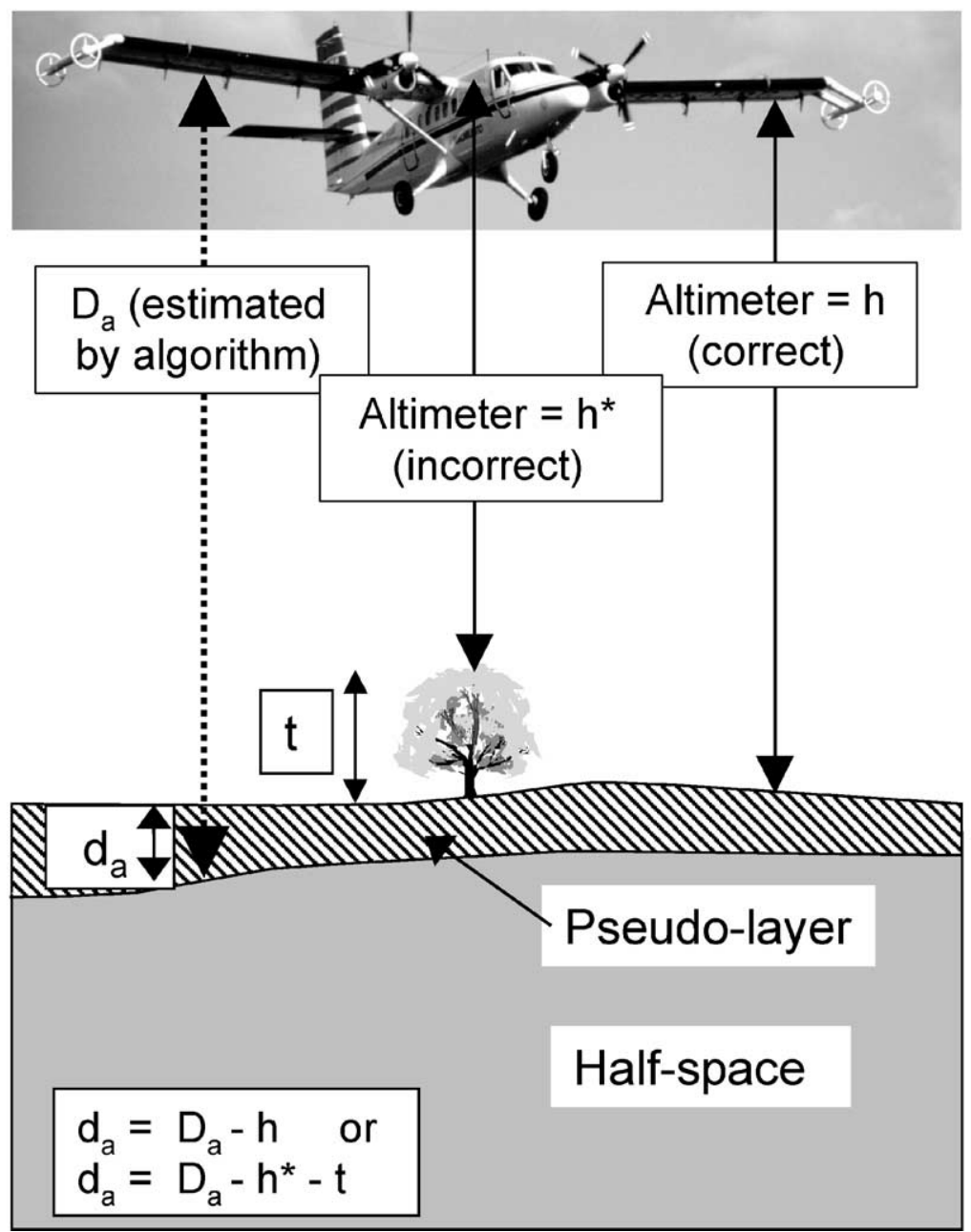

Figure 2. Illustration of parameter relationships involved in the pseudo-layer half-space calculation. The sensor separation is $r$. The on-board altimeter provides a correct elevation of $\mathrm{h}$ or underestimated $\mathrm{h} *$ when elevated features are encountered. Apparent distance (to half-space) is $D_{a}$ and formulae give the apparent depth $\left(d_{a}\right)$ below ground surface. 

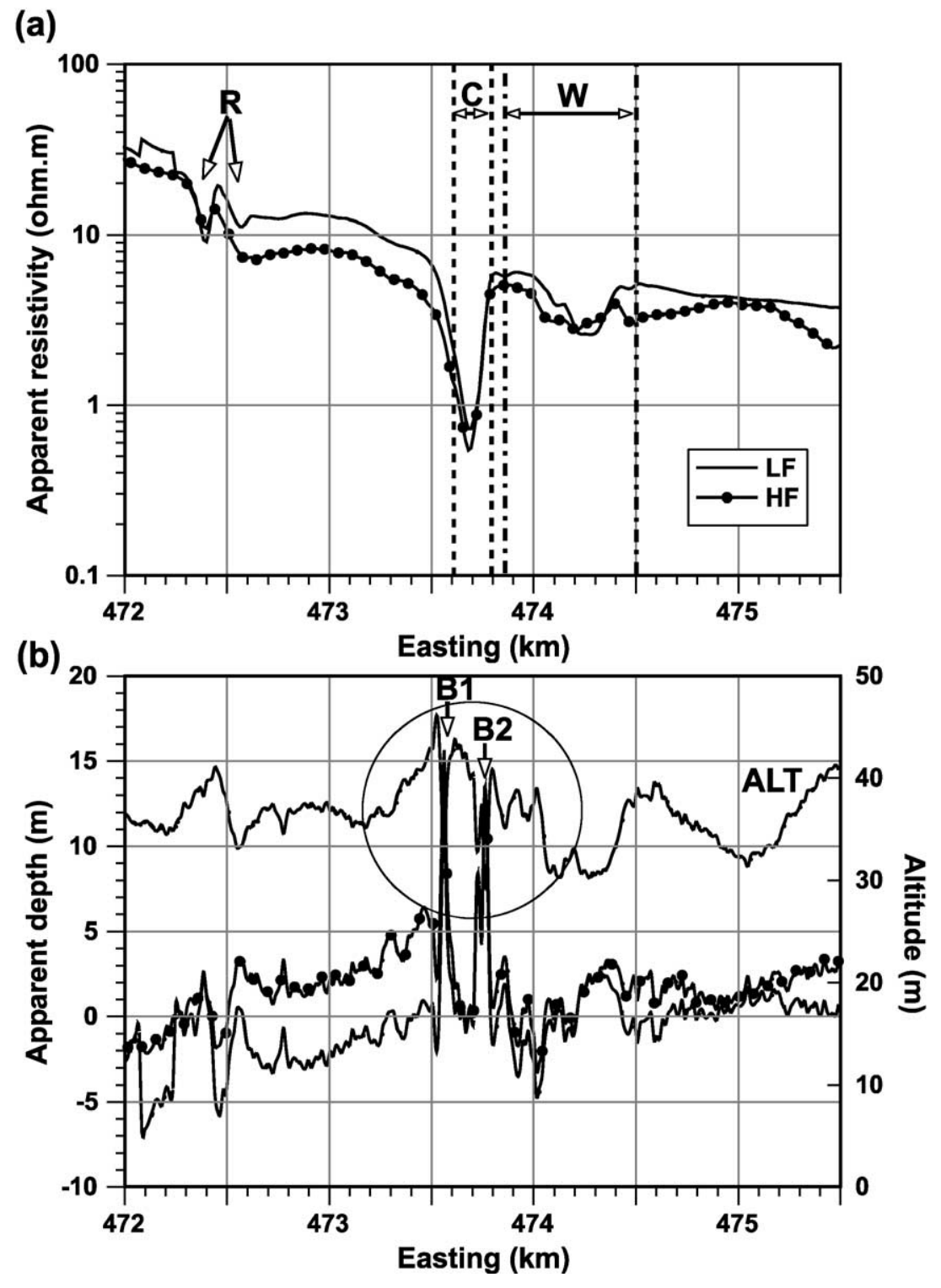

Figure 3. Fraser pseudo-layer half-space parameters along E-W flight line 420. (a) apparent resistivities at $3.1 \mathrm{kHz}$ (LF) and $14.4 \mathrm{kHz}$ (HF). Positions of two roads (R), the cement works (C) and the waste disposal site (W) are indicated. (b) Apparent depth at 3.1 $\mathrm{kHz}$ (LF) and $14.4 \mathrm{kHz}$ (HF), together with flight altitude (ALT, right axis). Circle denotes perturbations caused by buildings (B1 and B2) in the cement works area. 

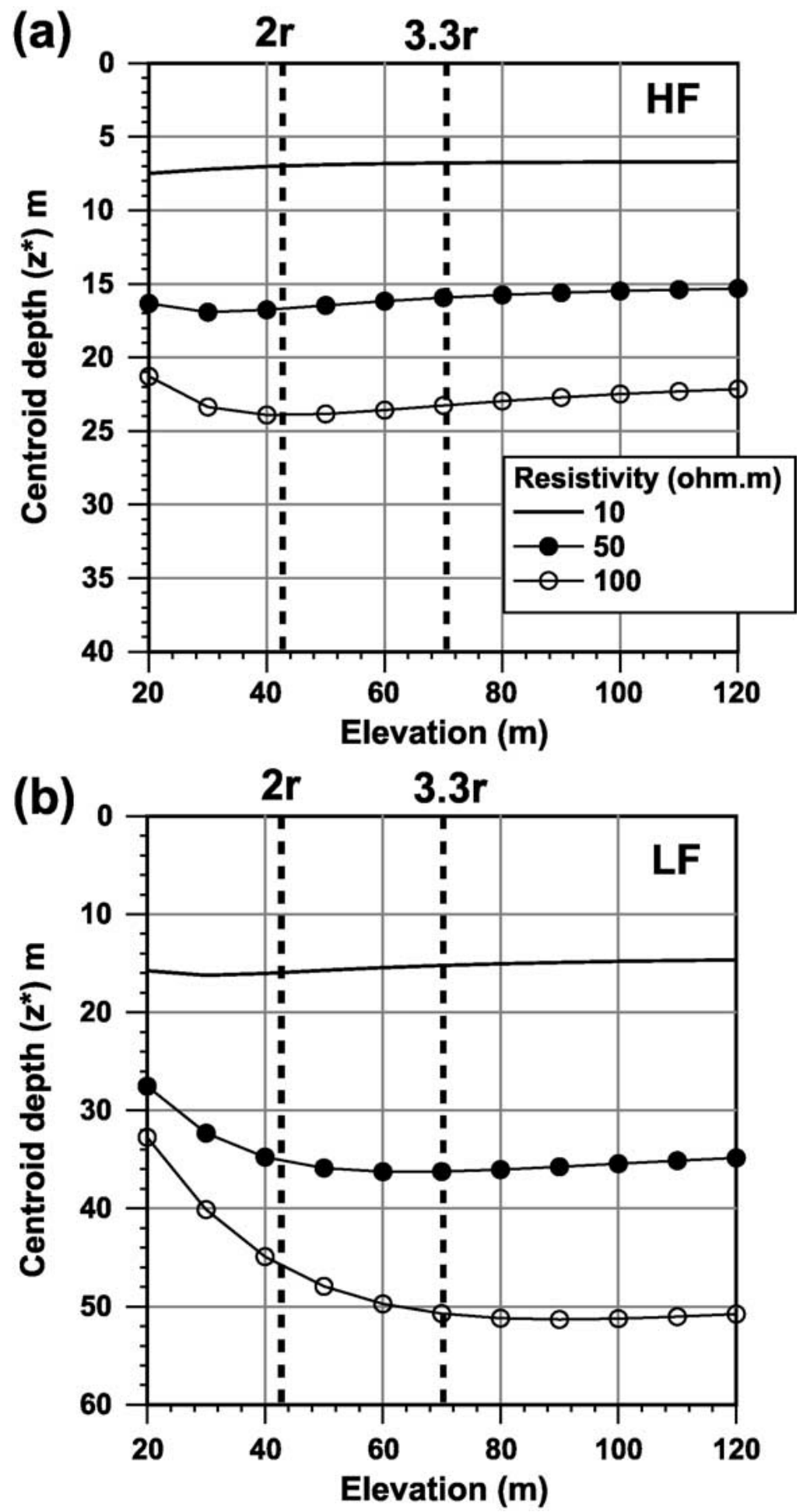

Figure 4. Centroid depths calculated for 3 half-space resistivities and for elevations in the range 20 to $120 \mathrm{~m}$ using a sensor separation (r) of $21.34 \mathrm{~m}$. (a) $14.4 \mathrm{kHz}$ (HF). (b) $3.1 \mathrm{kHz}$ (LF). 


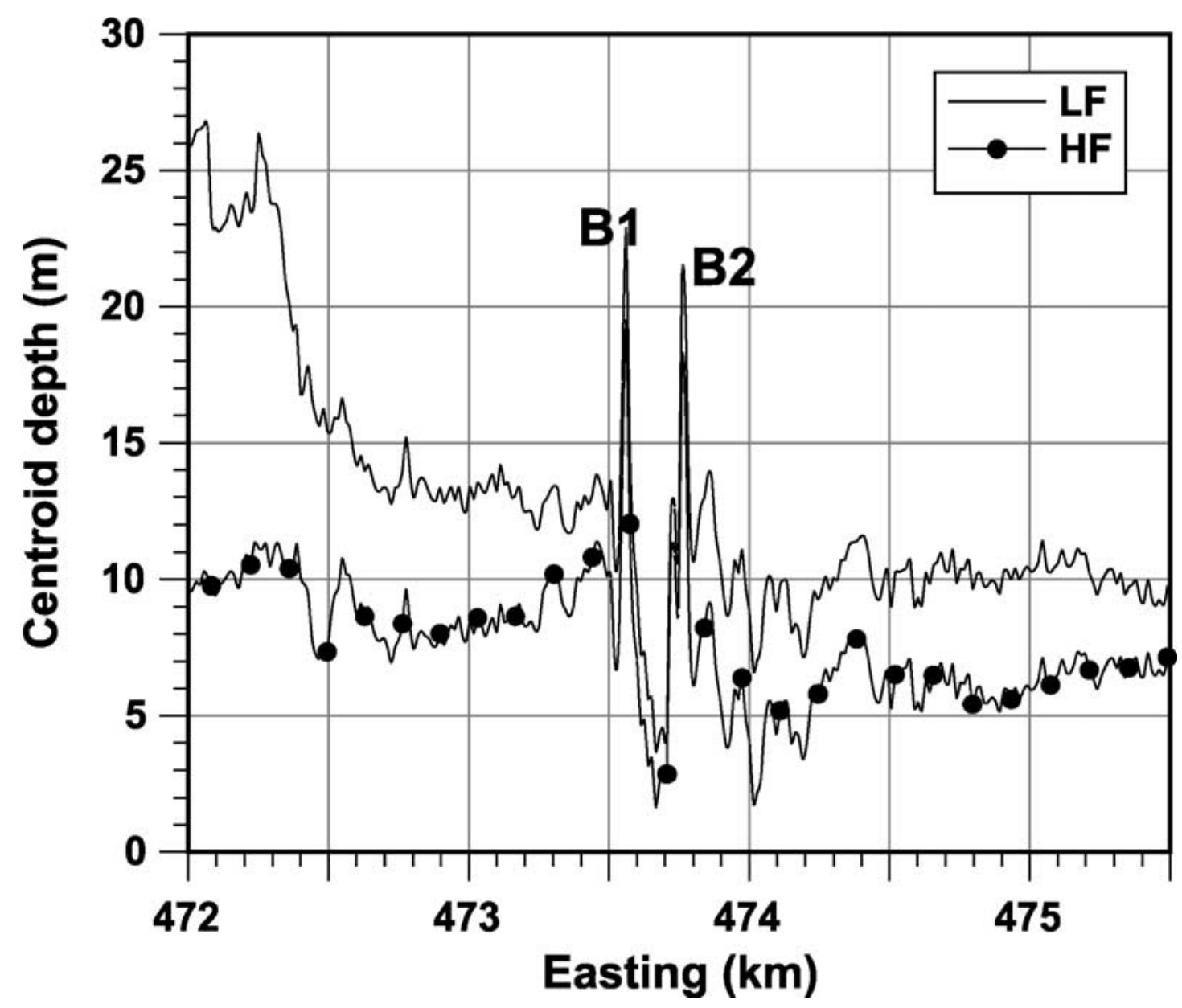

Figure 5. Centroid depths along E-W flight line 420 at $3.1 \mathrm{kHz}$ (LF) and $14.4 \mathrm{kHz}$ (HF). The influence of buildings B1 and B2 is indicated. 

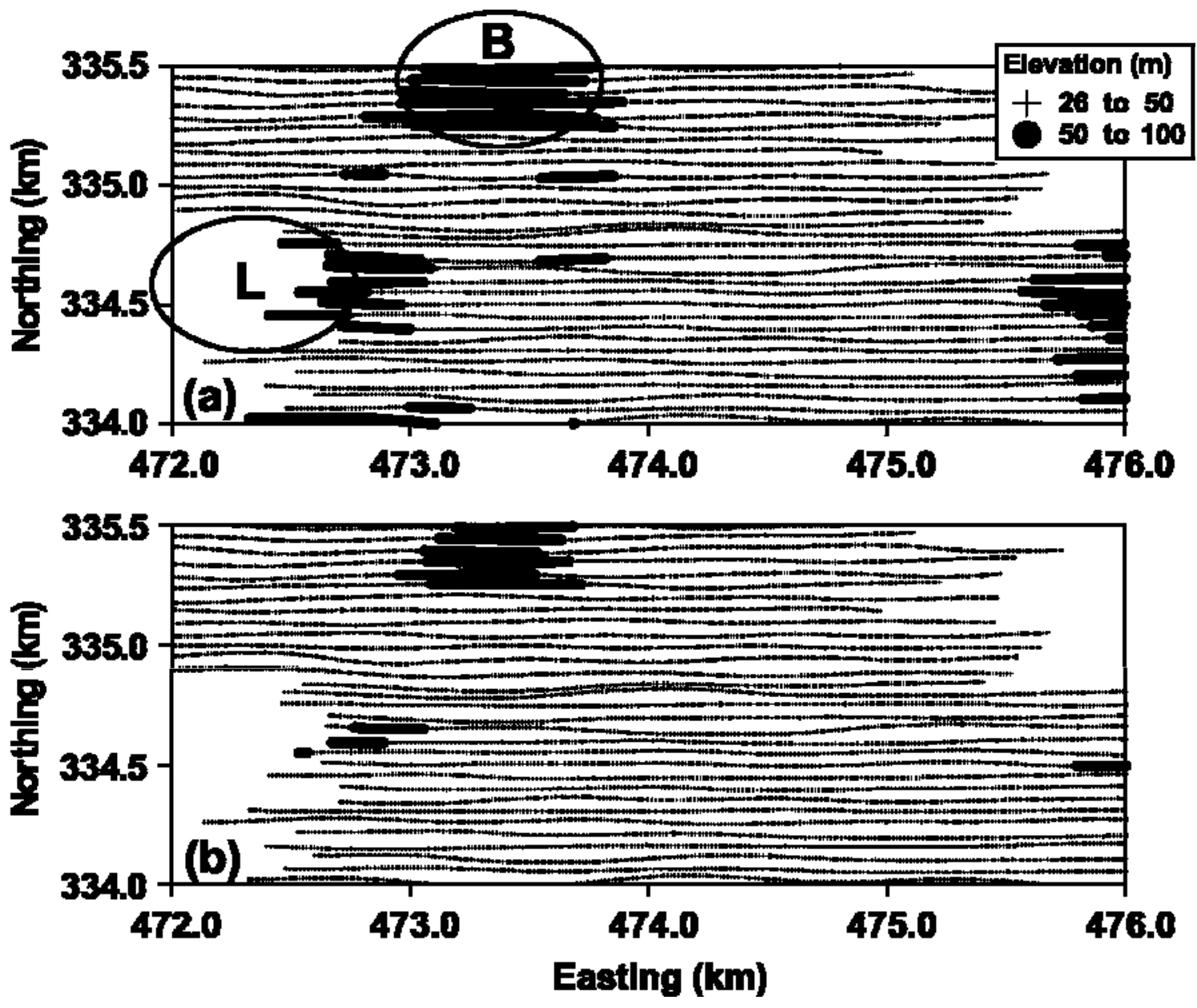

Figure 6. Results shown as classified symbol values along flight lines for the Langar survey area. (a) Elevation, values from 26 to $50 \mathrm{~m}$ shown as light symbols, values $>50 \mathrm{~m}$ shown as bold circles. The two ellipses denote the villages of Barnstone (B) and Langar ( $\mathrm{L}$ ). (b) Bold symbols denote points where the centroid depth $z^{*}(14.4 \mathrm{kHz})>z^{*}(3.1 \mathrm{kHz})$. 

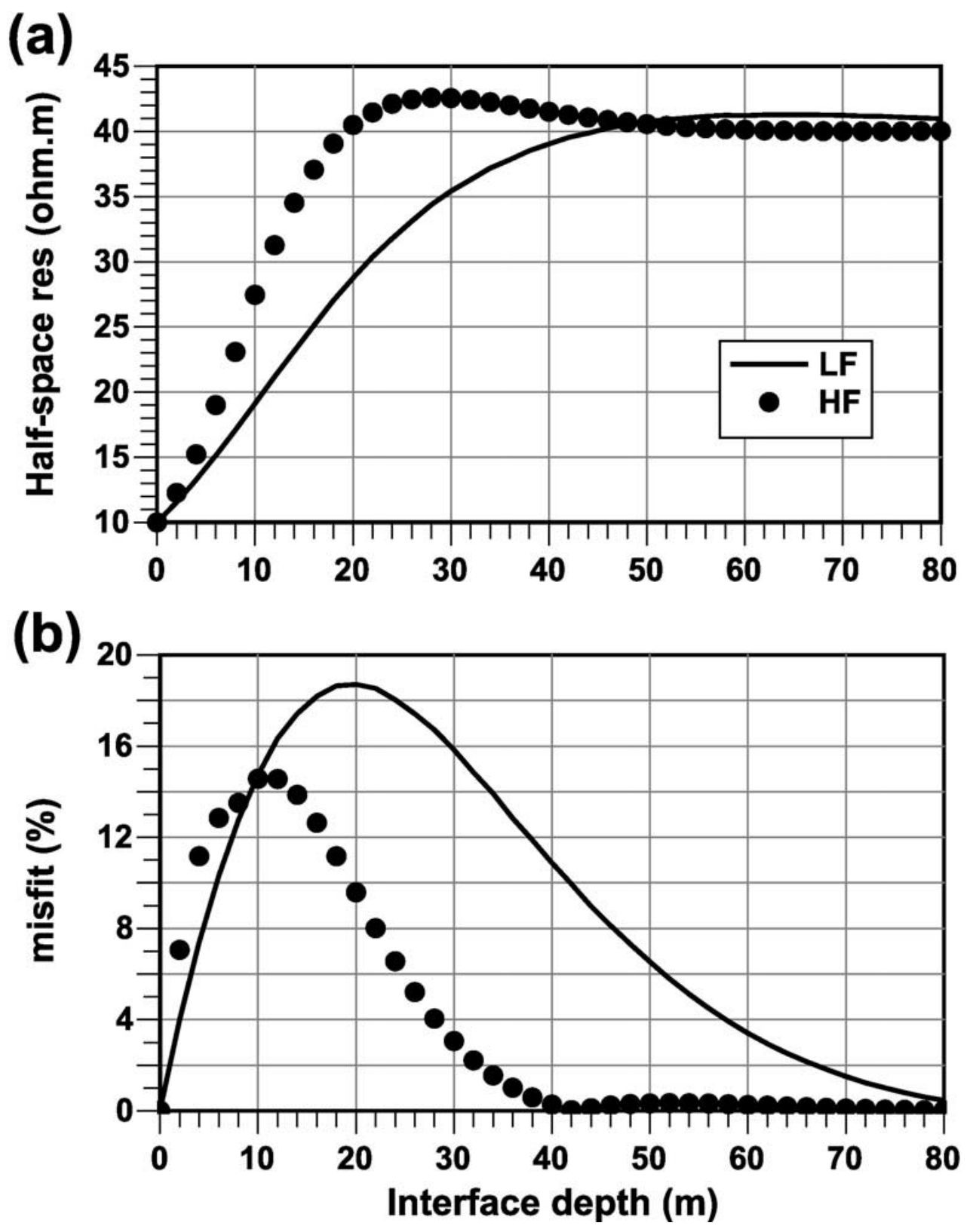

Figure 7. 1D inversion results for theoretical data from a 2-layer case with a 40 ohm.m cover above a $10 \mathrm{ohm} . \mathrm{m}$ halfspace, with interface depths ranging from 0 (a $10 \mathrm{ohm} . \mathrm{m}$ halfspace) to $80 \mathrm{~m}$. The inversion attempts to fit a half-space model for each of the two frequencies ( $\mathrm{LF}=3.1 \mathrm{kHz}, \mathrm{HF}=14.4 \mathrm{kHz}$ ). (a) apparent resistivities (ohm.m). (b) misfit (\%) calculated according to equation (14). 


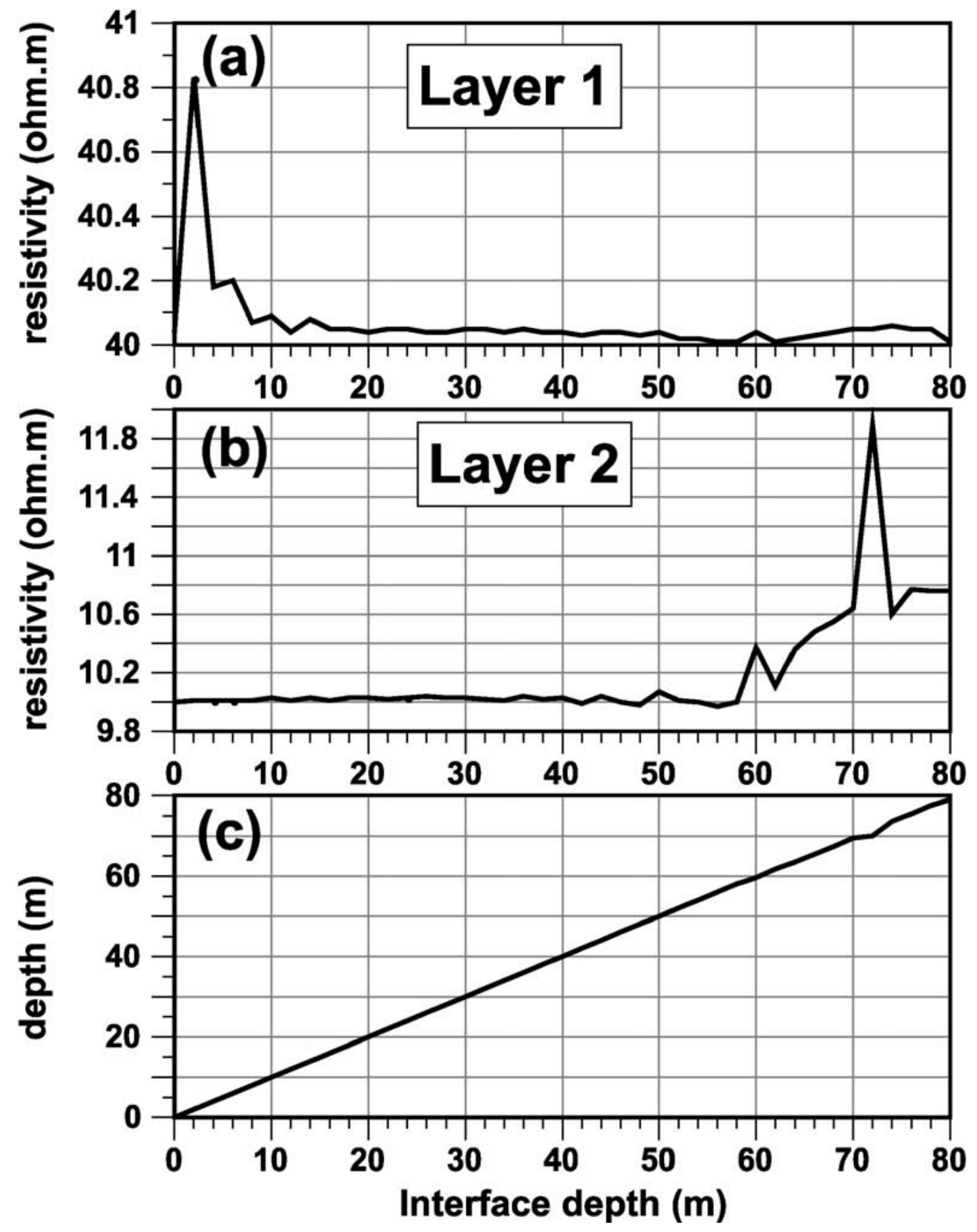

Figure 8. 1D inversion results for theoretical data from a 2-layer case with a $40 \mathrm{ohm} . \mathrm{m}$ cover above a 10 ohm.m halfspace, with interface depths ranging from 0 (a 10 ohm.m halfspace) to $80 \mathrm{~m}$. The inversion attempts to fit a 2-layer model using both frequencies. (a) resistivity of Layer 1 (ohm.m). (b) resistivity of Layer 2 (ohm.m). (c) depth of interface (m). 

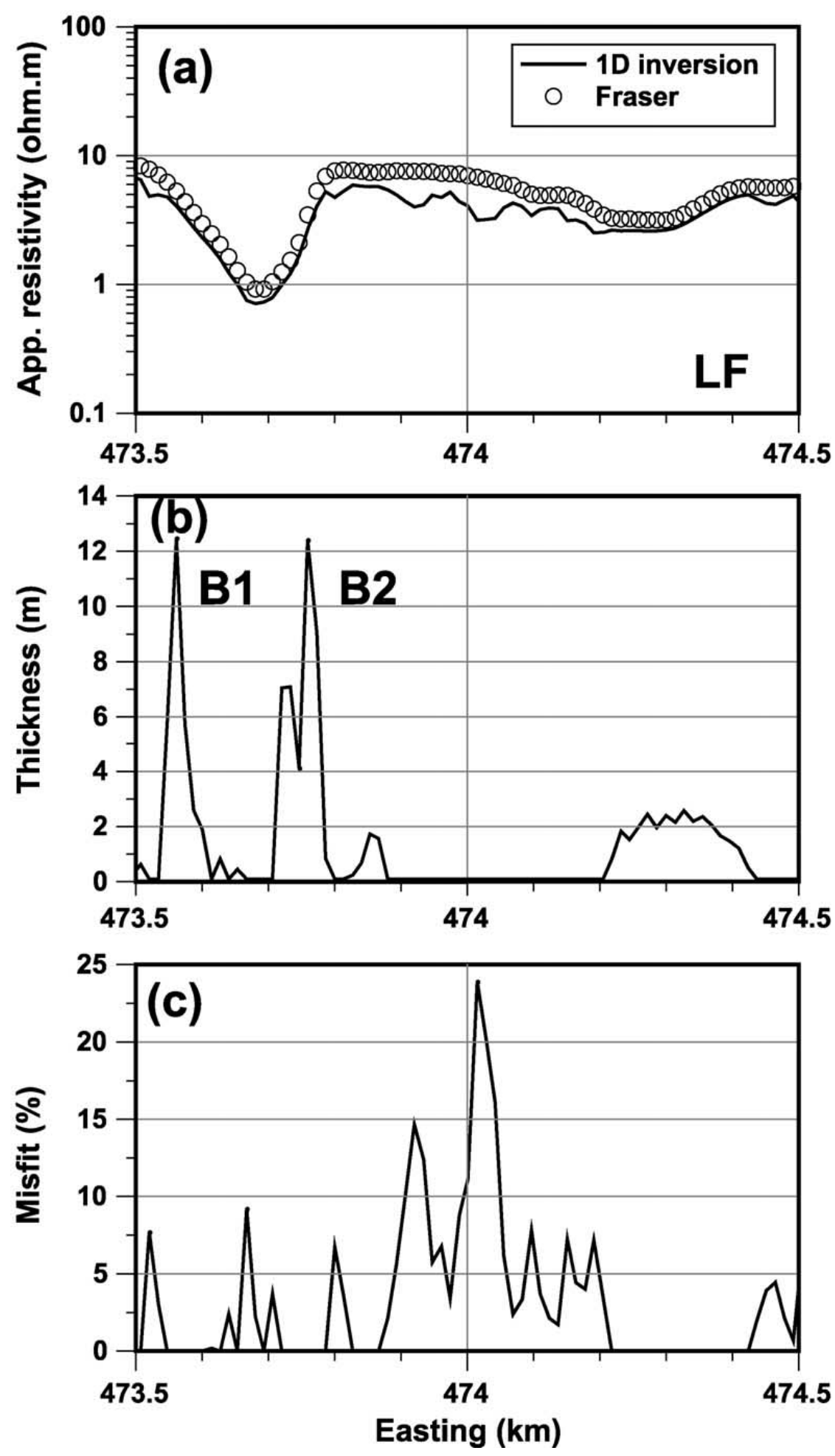

Figure 9. Half-space model results obtained along the central $1 \mathrm{~km}$ profile of E-W flight line 420. (a) LF (3.1 kHz) apparent resistivity. Fraser pseudo-layer half-space (symbols), 1D inversion (line). (b) Thickness of resistive at-surface layer (1D inversion), with influence of buildings (B1, B2) noted. (c) Misfit (\%) calculated according to equation (14). 

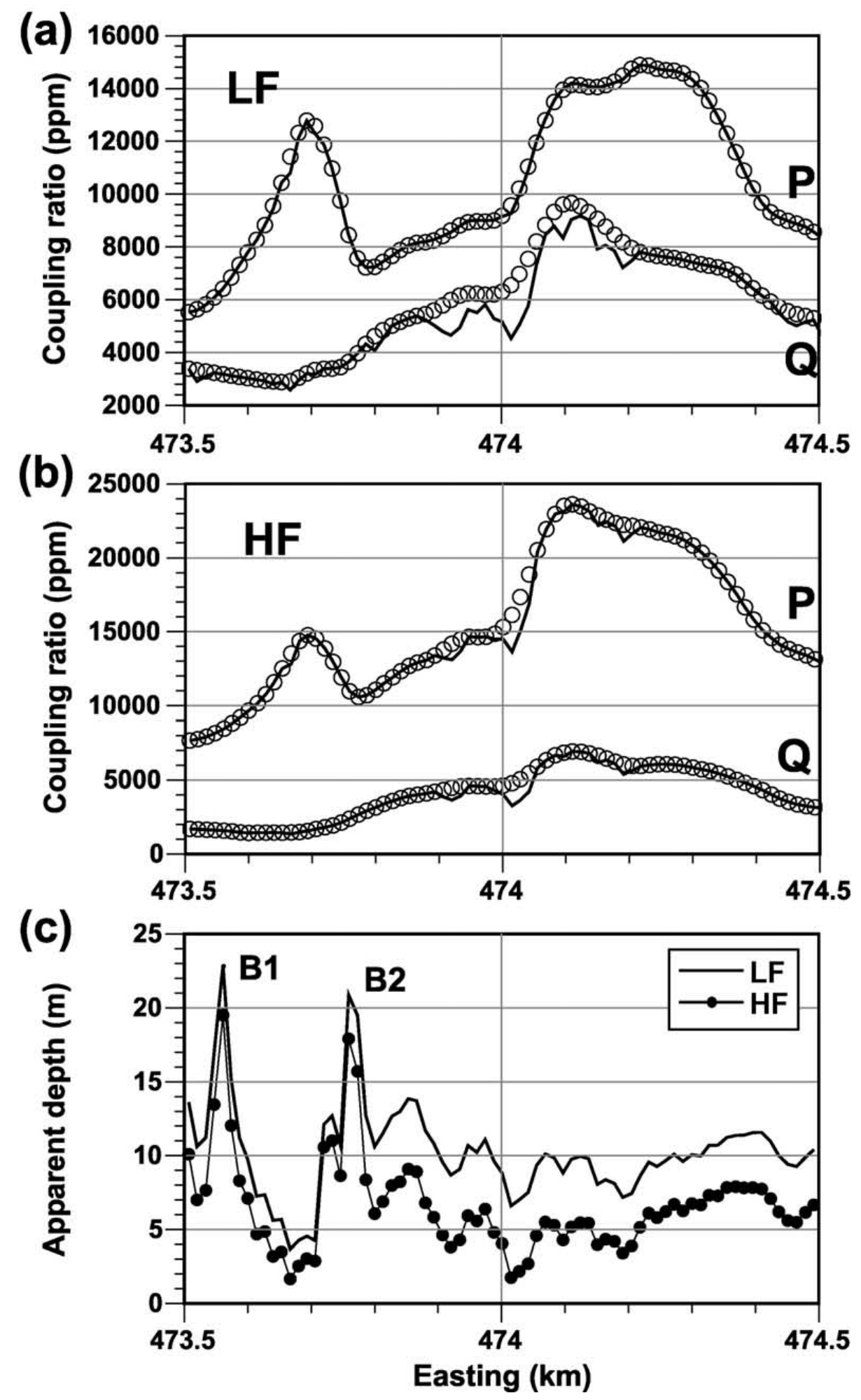

Figure 10. Half-space model results obtained along the central $1 \mathrm{~km}$ profile of E-W flight line 420. (a) Comparison of LF (3.1 kHz) coupling ratios, observed (symbol) and modelled (line), in-phase (P) and in-quadrature (Q) components. (b) Comparison of HF $(14.4 \mathrm{kHz})$ coupling ratios, observed (symbol) and modelled (line), in-phase (P) and in-quadrature (Q) components. (c) LF and HF apparent depth estimates obtained from Fraser pseudo-layer half-space algorithm, with influence of buildings (B1, B2) noted. 

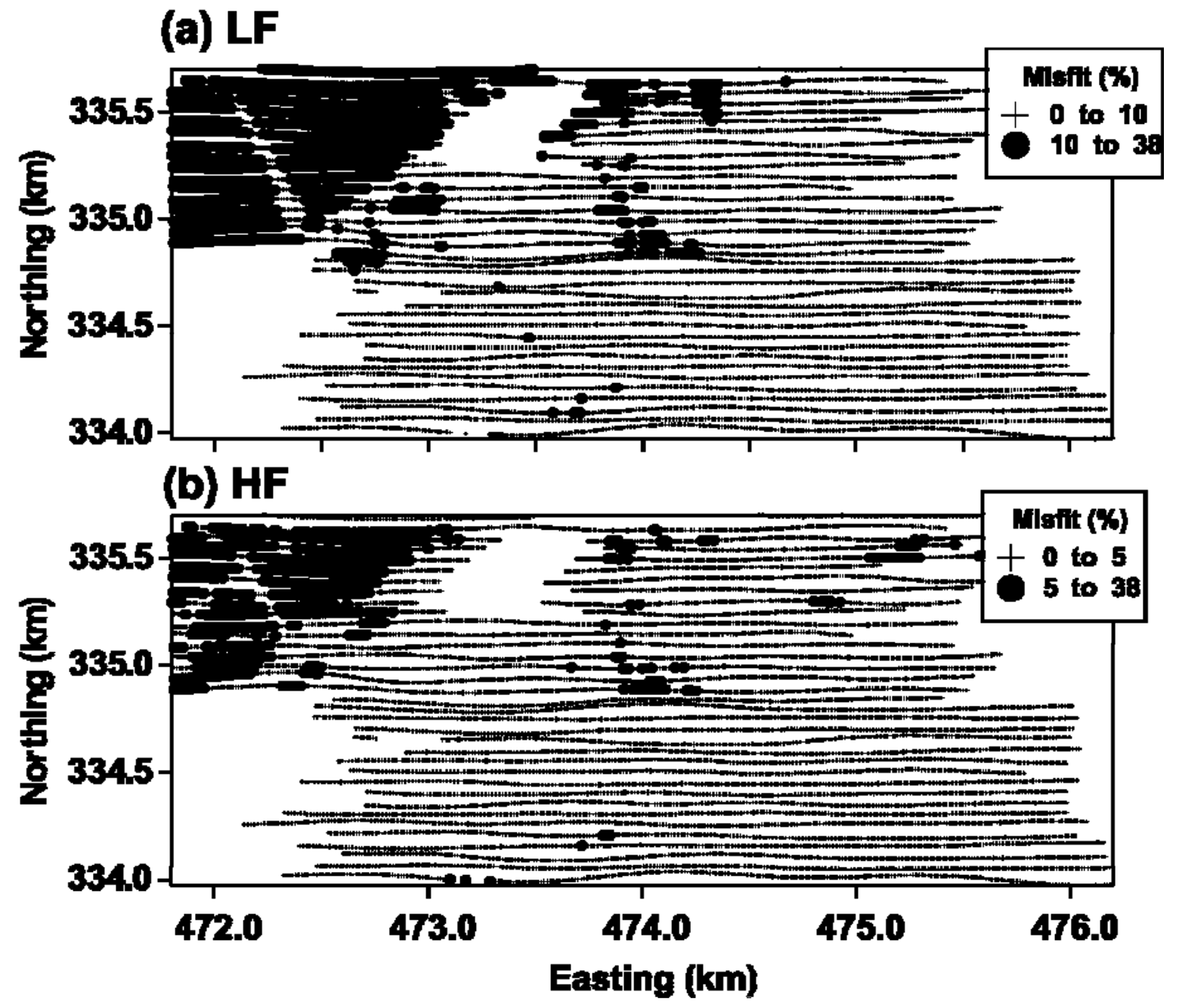

Figure 11. 1D inversion misfits shown as classified symbol values along flight lines for the Langar survey area. Data have been pre-processed according to Weidelt's inequality condition applied to centroid depth. (a) LF ( $3.1 \mathrm{kHz}$ ) misfit, values from 0 to $10 \%$ shown as light symbols, values $>10 \%$ shown as bold circles. (b) $\mathrm{HF}(14.4 \mathrm{kHz})$ misfit, values from 0 to $5 \%$ shown as light symbols, values $>5 \%$ shown as bold circles. 


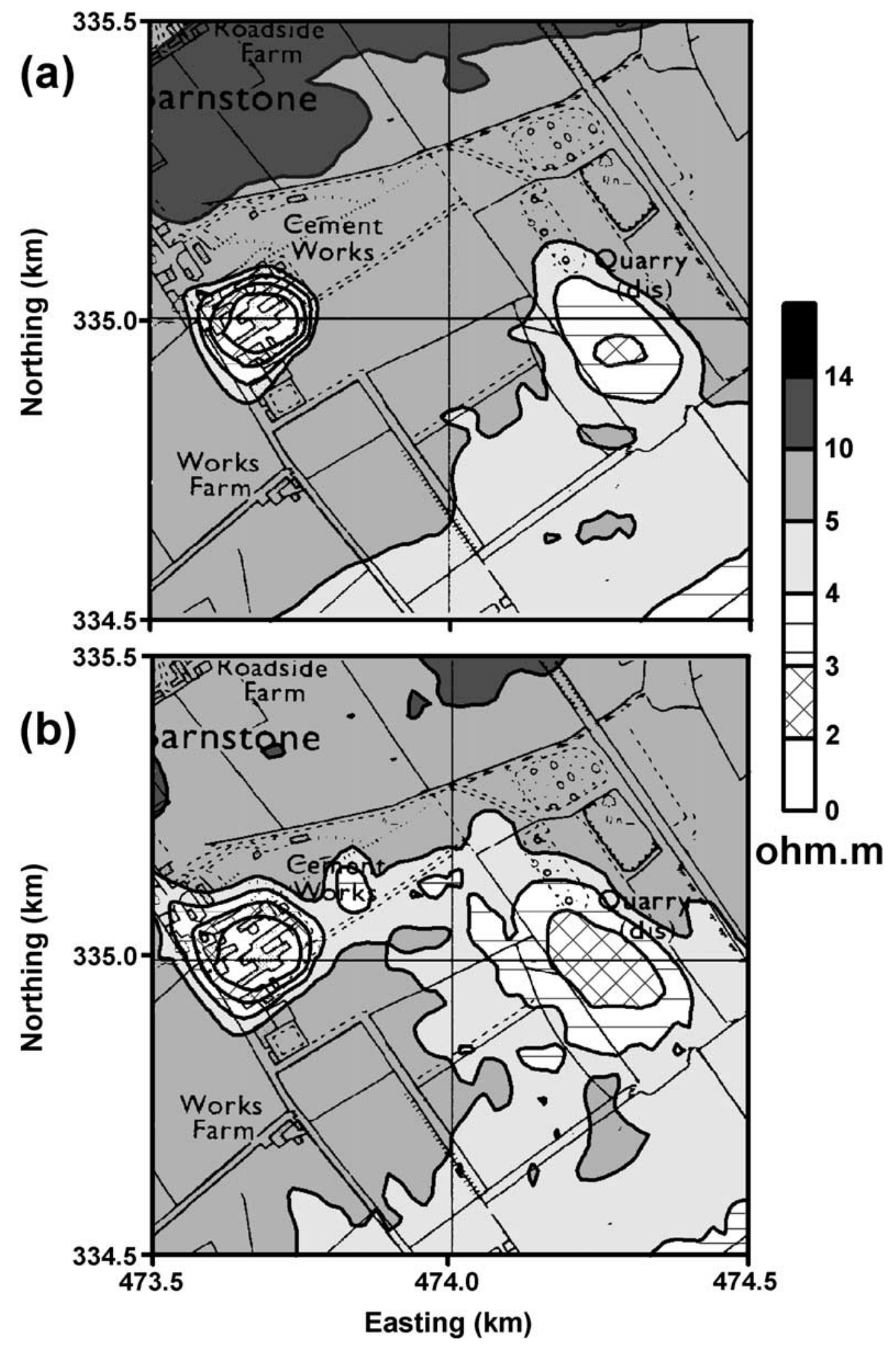

Figure 12. Comparison of (a) Fraser half-space and (b) 1D inversion, LF (3.1 kHz) half-space resistivity results across the central $1 \times 1 \mathrm{~km}$ area containing cement works and land-fill. The base map is reproduced from the OS map by British Geological Survey with the permission of Ordnance Survey on behalf of The Controller of Her Majesty's Stationery Office, (C) Crown copyright. All rights reserved. 


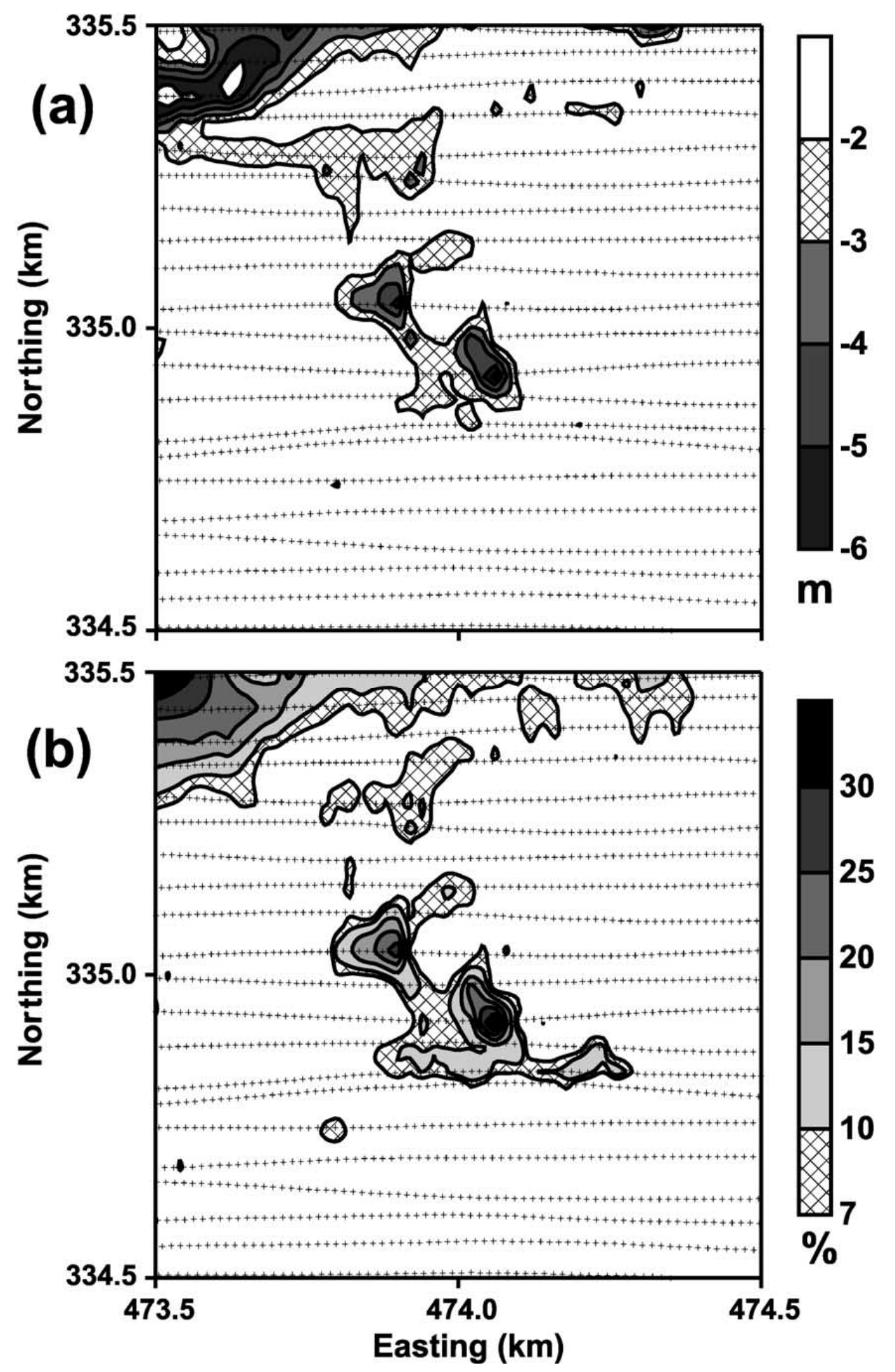

Figure 13. Comparison of (a) negative apparent depth and (b) 1D inversion misfit for LF $(3.1 \mathrm{kHz}$ ) half-space results across the central $1 \times 1 \mathrm{~km}$ area containing cement works and land-fill. (a) Only negative apparent depths (0 to $-6 \mathrm{~m})$ are contoured. (b) Only misfits > $7 \%$ are contoured. Background shows data sampling density of E-W flight lines. 